\title{
Meta-analysis of mouse transcriptomic studies supports a context-dependent astrocyte reaction in acute CNS injury versus neurodegeneration
}

\author{
Sudeshna Das ${ }^{1,2,3,4+}$, Zhaozhi Li ${ }^{1,2+}$, Ayush Noori ${ }^{1,2}$, Bradley T. Hyman ${ }^{2,3,4}$ and Alberto Serrano-Pozo ${ }^{2,3,4^{*}}$ (D)
}

\begin{abstract}
Background: Neuronal damage in acute CNS injuries and chronic neurodegenerative diseases is invariably accompanied by an astrocyte reaction in both mice and humans. However, whether and how the nature of the CNS insult-acute versus chronic-influences the astrocyte response, and whether astrocyte transcriptomic changes in these mouse models faithfully recapitulate the astrocyte reaction in human diseases remains to be elucidated. We hypothesized that astrocytes set off different transcriptomic programs in response to acute versus chronic insults, besides a shared "pan-injury" signature common to both types of conditions, and investigated the presence of these mouse astrocyte signatures in transcriptomic studies from human neurodegenerative diseases.
\end{abstract}

Methods: We performed a meta-analysis of 15 published astrocyte transcriptomic datasets from mouse models of acute injury $(n=6)$ and chronic neurodegeneration $(n=9)$ and identified pan-injury, acute, and chronic signatures, with both upregulated (UP) and downregulated (DOWN) genes. Next, we investigated these signatures in 7 transcriptomic datasets from various human neurodegenerative diseases.

Results: In mouse models, the number of UP/DOWN genes per signature was 64/21 for pan-injury and 109/79 for acute injury, whereas only 13/27 for chronic neurodegeneration. The pan-injury-UP signature was represented by the classic cytoskeletal hallmarks of astrocyte reaction (Gfap and Vim), plus extracellular matrix (i.e., Cd44, Lgals 1, Lgals3, Timp1), and immune response (i.e., C3, Serping1, Fas, Stat1, Stat2, Stat3). The acute injury-UP signature was enriched in protein synthesis and degradation (both ubiquitin-proteasome and autophagy systems), intracellular trafficking, and anti-oxidant defense genes, whereas the acute injury-DOWN signature included genes that regulate chromatin structure and transcriptional activity, many of which are transcriptional repressors. The chronic neurodegeneration-UP signature was further enriched in astrocyte-secreted extracellular matrix proteins (Lama4, Cyr61, Thbs4), while the DOWN signature included relevant genes such as Agl (glycogenolysis), S1pr1 (immune modulation), and Sod2 (anti-oxidant). Only the pan-injury-UP mouse signature was clearly present in some human (Continued on next page)

\footnotetext{
* Correspondence: aserrano1@mgh.harvard.edu

†Sudeshna Das and Zhaozhi Li contributed equally to this work.

${ }^{2}$ Department of Neurology, Massachusetts General Hospital, Boston, MA 02114, USA

${ }^{3}$ Massachusetts Alzheimer's Disease Research Center, 114 16th street, Suite 2012, Charlestown, MA 02129, USA

Full list of author information is available at the end of the article
}

(c) The Author(s). 2020 Open Access This article is licensed under a Creative Commons Attribution 4.0 International License, which permits use, sharing, adaptation, distribution and reproduction in any medium or format, as long as you give appropriate credit to the original author(s) and the source, provide a link to the Creative Commons licence, and indicate if changes were made. The images or other third party material in this article are included in the article's Creative Commons licence, unless indicated otherwise in a credit line to the material. If material is not included in the article's Creative Commons licence and your intended use is not permitted by statutory regulation or exceeds the permitted use, you will need to obtain permission directly from the copyright holder. To view a copy of this licence, visit http://creativecommons.org/licenses/by/4.0/. The Creative Commons Public Domain Dedication waiver (http://creativecommons.org/publicdomain/zero/1.0/) applies to the data made available in this article, unless otherwise stated in a credit line to the data. 
(Continued from previous page)
neurodegenerative transcriptomic datasets.

Conclusions: Acute and chronic CNS injuries lead to distinct astrocyte gene expression programs beyond their common astrocyte reaction signature. However, caution should be taken when extrapolating astrocyte transcriptomic findings from mouse models to human diseases.

Keywords: Acute CNS injury, Astrocyte reaction, Meta-analysis, Neurodegenerative diseases, Transcriptomics

\section{Background}

Neuronal loss in central nervous system (CNS) acute injuries and chronic neurodegenerative diseases is invariably accompanied by an astrocyte reaction, which has been traditionally depicted by an increased glial fibrillary acidic protein (GFAP) immunoreactivity. However, thanks to the improvement of cell purification protocols and the development of transcriptomic methodologies (microarray and RNA-seq), the complexity and heterogeneity of this astrocyte reaction is emerging above and beyond this increased GFAP immunoreactivity. One area of uncertainty is whether there is any disease-specificity in astrocyte reaction or, conversely, this is just a nonspecific response of astrocytes to any kind of neuronal injury. More specifically, whether reactive astrocytes could be neurotoxic in certain pathological conditions and neuroprotective in others is an area of active research. For example, it has been proposed that reactive astrocytes are neurotoxic (so called A1 astrocytes) in the lipopolysaccharide (LPS)-induced sepsis mouse model, but neuroprotective (termed A2 astrocytes) in the middle cerebral artery occlusion (MCAO) stroke mouse model $[1,2]$. Another controversial question is whether astrocyte proliferation is a universal feature of astrocyte reaction. For example, astrocyte proliferation has been demonstrated in acute injury conditions such as traumatic brain injury (TBI) and stroke [3-5] but appears more limited in the context of chronic neurodegenerative diseases [5-9].

We hypothesized that astrocytes set off different transcriptomic programs in response to acute versus chronic disease, but that a common pan-injury signature underlies both types of conditions. To test this hypothesis, we took advantage of publicly available microarray and RNA-seq mouse astrocyte transcriptomic datasets from acute lesions [LPS-induced sepsis, MCAO stroke, spinal cord injury (SCI), and 1-methyl-4-phenyl-1,2,3,6-tetrahydropyridine (MPTP)] and chronic neurodegenerative disease models [amyotrophic lateral sclerosis (ALS) and Alzheimer's disease (AD)], and applied bioinformatics tools [gene set enrichment analysis (GSEA) and metaanalysis]. Specifically, we asked whether (1) the previously reported A1, A2, and pan-reactive signatures can be extrapolated to conditions beyond LPS-induced sepsis and MCAO stroke; (2) distinct acute, chronic, and pan- injury (common to acute and chronic conditions) signatures can be identified; (3) reactive astrocytes in these conditions activate proliferative pathways as much as inflammatory cascades; and (4) astrocyte transcriptomic signatures obtained from mouse models correlate with changes in astrocyte gene expression levels in the corresponding human diseases.

\section{Methods}

All analyses were conducted using $\mathrm{R}$ version 3.5.1 [10]

\section{Mouse gene expression analysis}

Publicly available transcriptomic datasets of mouse astrocytes were identified either by using search terms in Gene Expression Omnibus (GEO) [11] or from relevant literature (Table 1). Microarray data were processed and normalized using RMA package in R. For RNA-seq datasets, we used fragments per kilobase of transcript per million mapped reads (FPKM) values whenever available; when only the raw sequencing fastq files were available, we used the salmon package to process and estimate transcript abundance [24]. Differentially expressed genes (DEGs) were identified using limma [25] and voom+ limma [26] as genes with a statistically significant difference in expression level $(p<0.05)$ between the diseased (i.e., transgenic) and control (i.e., wild-type) mice.

\section{Meta-analysis of mouse transcriptomic studies}

Meta-analyses were conducted using the sumz function in the metap package in $\mathrm{R}$, which first converts the $P$ values into $Z$ scores, and then computes the composite $Z$ score [27]. Square root of the sample sizes was used as weights in the sumz procedure to control for the number of samples in each study. The $p$ values were corrected for multiple comparisons using a false discovery rate $($ FDR $)<5 \%$. We conducted meta-analyses within acute injury and neurodegenerative mouse studies separately. We identified the pan-injury signature as those genes that met two criteria: (1) had a statistically significant multiple-comparison-corrected meta $p$ value (meta $p<0.05)$ and (2) had a statistically significant $(p<0.05)$ differential expression in at least $33 \%$ of both acute injury and neurodegenerative mouse datasets. The chronic neurodegeneration-specific signature was defined as those genes with a statistically significant adjusted meta 
Table 1 Summary of publicly available mouse astrocyte transcriptomic datasets used in this study

\begin{tabular}{|c|c|c|c|c|c|c|c|c|c|c|}
\hline Label & Injury type & Comparison & N & $\begin{array}{l}\text { Sex } \\
(n \mathrm{M} / \mathrm{F})\end{array}$ & Age & CNS region & $\begin{array}{l}\text { Astrocyte } \\
\text { isolation } \\
\text { method }\end{array}$ & $\begin{array}{l}\text { RNA } \\
\text { method }\end{array}$ & Accession \# & Ref. \\
\hline$\overline{\mathrm{LPS}}$ & Acute & LPS vs placebo & $5 / 4$ & $5 \mathrm{M} / 4 \mathrm{M}$ & 30-35 days & $c t x+c c$ & $\begin{array}{l}\text { FACS of } \\
\text { Aldh1L1- } \\
\text { eGFP+ cells }\end{array}$ & Microarray & GSE35338 & [1] \\
\hline MCAO-1 & Acute & $\begin{array}{l}\text { MCAO vs sham } \\
\text { surgery }\end{array}$ & $3 / 3$ & $3 \mathrm{M} / 3 \mathrm{M}$ & 30-35 days & $\begin{array}{l}\text { ctx+cct } \\
\text { hipp+str }\end{array}$ & $\begin{array}{l}\text { FACS of } \\
\text { Aldh1L1- } \\
\text { eGFP+ cells }\end{array}$ & Microarray & GSE35338 & [1] \\
\hline MCAO-2 & Acute & $\begin{array}{l}\text { Transient MCAO } \\
\text { ipsi- vs contra and } \\
\text { control (no TMX) }\end{array}$ & $3 / 3$ & NA & $3-5$ months & Hemibrain & $\begin{array}{l}\text { Cx43-Cre-ERT/ } \\
\text { RiboTag }\end{array}$ & RNA-seq & GSE103783 & [12] \\
\hline SCl-1 & Acute & $\begin{array}{l}\mathrm{SCl} \text { at T10 vs } \\
\text { non-injured }\end{array}$ & $4 / 4$ & $4 \mathrm{~F} / 4 \mathrm{~F}$ & 2-4 months & Spinal cord & $\begin{array}{l}\text { mGFAP-Cre- } \\
\text { RiboTag }\end{array}$ & RNA-seq & GSE76097 & [13] \\
\hline $\mathrm{SCl}-2$ & Acute & $\begin{array}{l}\mathrm{SCl} \text { at T9 (hemi- } \\
\text { and full transection } \\
\text { vs non-injured) }\end{array}$ & $9 / 3$ & $9 \mathrm{M} / 3 \mathrm{M}$ & 12 weeks & Spinal cord & $\begin{array}{l}\text { FACS of } \\
\text { Aldh1L1- } \\
\text { eGFP+ cells }\end{array}$ & RNA-seq & GSE96054 & [14] \\
\hline MPTP-24 h & Acute & $\begin{array}{l}\text { MPTP vs vehicle } \\
\text { (sac } 24 \mathrm{~h} \text { post- } \\
\text { single i.p. inj.) }\end{array}$ & $3 / 3$ & $3 F / 3 F$ & 4-7 months & str & $\begin{array}{l}\text { TRAP of Aldh1L1- } \\
\text { eGFP-L10a }\end{array}$ & Microarray & $\begin{array}{l}\text { https://doi.org/10. } \\
\text { 17632/ktgcp4mtk2.1 }\end{array}$ & [15] \\
\hline SOD1-G93A-1 & Chronic & G93A SOD1 vs wt & $4 / 3$ & NA & 90 days & Spinal cord & $\begin{array}{l}\text { FACS Aldh1L1- } \\
\text { eGFP/G93A SOD1 }\end{array}$ & Microarray & GSE111031 & [16] \\
\hline SOD1-G93A-2 & Chronic & G93A SOD1 vs wt & $3 / 3$ & $3 \mathrm{M} / 3 \mathrm{M}$ & 120 days & Spinal cord & $\begin{array}{l}\text { LCM of Aldh1L1+ } \\
\text { cells }\end{array}$ & Microarray & GSE69166 & [17] \\
\hline SOD1-G37R & Chronic & G37R SOD1 vs wt & $4 / 6$ & $4 \mathrm{M} / 6 \mathrm{M}$ & 8 months & Spinal cord & $\begin{array}{l}\text { TRAP of Aldh1L1- } \\
\text { EGFP-L10a }\end{array}$ & RNA-seq & GSE74724 & [18] \\
\hline APPPS1-1 & Chronic & APPswePS1dE9 vs wt & $4 / 4$ & NA & $15-18$ months & Whole ctx & $\begin{array}{l}\text { FACS with } \\
\text { Glt-1 Ab }\end{array}$ & Microarray & GSE74615 & [19] \\
\hline APPPS1-2 & Chronic & APPswePS1dE9 vs wt & $4 / 4$ & NA & $15-18$ months & Whole ctx & $\begin{array}{l}\text { FACS of GFAP- } \\
\text { GFP cells }\end{array}$ & Microarray & GSE74614 & [20] \\
\hline APPPS1-3 & Chronic & $\begin{array}{l}\text { APPswePS1dE9-GFP } \\
\text { vs wt-GFP }\end{array}$ & $4 / 7$ & $4 \mathrm{M} / 7 \mathrm{M}$ & 9 months & CA1 hipp & $\begin{array}{l}\text { FACS of eGFP+ } \\
\text { cells }\end{array}$ & RNA-seq & GSE108520 & [21] \\
\hline PS2APP-1 & Chronic & PS2APP vs wt & $4 / 5$ & $2 \mathrm{M} 2 \mathrm{~F} / 1 \mathrm{M} 4 \mathrm{~F}$ & 13 months & Whole brain & $\begin{array}{l}\text { FACS with } \\
\text { GFAP Ab }\end{array}$ & RNA-seq & GSE75431 & [22] \\
\hline PS2APP-2 & Chronic & PS2APP vs wt & $5 / 5$ & NA & 11.5 months & Whole brain & $\begin{array}{l}\text { FACS with } \\
\text { GFAP Ab }\end{array}$ & RNA-seq & GSE129770 & [23] \\
\hline P301S-tau & Chronic & $\begin{array}{l}\text { hMAPT-P301S } \\
\text { tau vs wt }\end{array}$ & $5 / 6$ & $5 \mathrm{M} / 6 \mathrm{M}$ & 6 months & Whole ctx & $\begin{array}{l}\text { FACS with } \\
\text { GFAP Ab }\end{array}$ & RNA-seq & GSE129797 & [23] \\
\hline
\end{tabular}

Abbreviations: $A b$ antibody, Aldh1L1 aldehyde dehydrogenase $1 \mathrm{~L} 1, A P P$ amyloid- $\beta$ precursor protein, CA1 cornus ammonis 1, $c C$ corpus callosum, CNS central nervous system, ctx cortex, $C x 43$ connexin-43, eGFP enhanced green fluorescent protein, FACS fluorescence-activated cell sorting, GFAP glial fibrillary acidic protein, Glt1 glutamate transporter 1, i.p. intra-peritoneal, LCM laser capture microdissection, LPS lipopolysaccharide, MAPT microtubule-associated protein tau, MCAO middle cerebral artery occlusion, MPTP 1-methyl-4-phenyl-1,2,3,6-tetrahydropyridine, PS1/2 presenilin 1/2, sac sacrifice, SCI spinal cord injury, SOD1 superoxide dismutase 1, TRAP translating ribosome affinity purification

$p$ value (meta $p<0.05$ ) in the neurodegenerative metaanalysis, which had a statistically significant differential expression $(p<0.05)$ in $33 \%$ or more neurodegenerative studies but none of the acute injury datasets. Similarly, the acute injury-specific signature was defined as those genes with a statistically significant adjusted meta $p$ value (meta $p<0.05$ ) in the acute injury meta-analysis, which had a statistically significant differential expression $(p<0.05)$ in $33 \%$ or more acute injury studies but none of the chronic neurodegeneration datasets. DEGs were considered upregulated (UP) if the logarithm of the fold change (logFC) was $>0$ and downregulated (DOWN) if the $\operatorname{logFC}$ was $<0$. Although some of the datasets analyzed had some contamination from microglial genes $[17,18,21]$, this analytic approach minimized the probability of including these microglial genes from a single dataset in the final meta-analytic signatures. Moreover, we confirmed the expression of the resulting genes by astrocytes in a previously published RNA-seq study of cell subpopulations isolated from the mouse brain [28].

\section{Gene set enrichment analysis (GSEA)}

To identify signaling pathways, we searched for the terms "KAPPA", "NFAT", "MAPK", "JAK/STAT", "WNT/BETA-CATENIN", and "SONIC HEDGEHOG" within the KEGG, REACTOME, BIOCARTA, PID, and GO pathways compiled in the MSigDB version 6.2 [29] and obtained a total of 86 gene sets. Next, we performed gene set enrichment analysis (GSEA) [30, 31] to determine the enrichment of each of these gene sets in each of the 15 mouse astrocyte transcriptomic datasets and 
generated a heatmap with the normalized enrichment scores (NES) and another heatmap with the $-\log _{10}$ of the $p$ values. Next, we conducted a meta-analysis of the resulting GSEA $p$ values and ranked the gene sets in descending adjusted meta $p$ value, representing the relative relevance of these signaling pathways in the astrocytes from each of the mouse models.

\section{Validation of mouse astrocyte signatures in human transcriptomic datasets}

To validate the meta-analytic mouse transcriptomic signatures, we investigated the differential expression of each of the signature genes in human microarray and RNA-seq bulk tissue and astrocyte-specific datasets from AD, Parkinson's disease (PD), and ALS. Table 2 depicts the human datasets used in these analyses, with sample size, CNS region of interest, transcriptomic method, accession number, and reference. The AD datasets were analyzed by comparing individuals with Braak NFT V/VI (AD) versus Braak NFT 0/I/II (controls), as described previously [37]. The differential expression of diseased versus control individuals for the PD and ALS datasets was analyzed using limma. Violin plots were generated using ggplot2 version 3.2.1 [38] to represent the $\operatorname{logFC}$ of each signature gene in diseased versus control individuals.

\section{Results}

\section{Compilation of acute injury and neurodegenerative astrocyte transcriptomic datasets}

A total of 15 transcriptomic datasets from astrocytes isolated from mouse models were obtained from GEO. Dataset category (acute injury versus neurodegeneration), mouse model, mouse age and sex, CNS region, method of astrocyte isolation, GEO accession number, and literature reference for these datasets can be found in Table 1 . Mouse acute injury datasets $(n=6)$ included LPS-induced sepsis $(n=1)$ [1], MCAO stroke $(n=2)[1,12]$, SCI $(n=$ 2) $[13,14]$, and acute toxic parkinsonism (MPTP, $n=1$ ) [15]. For one of the stroke studies [1], only the dataset from 3 days after MCAO was analyzed, because gene expression changes were maximum 3 days and attenuated by 7 days after MCAO surgery. The MPTP dataset [15] was classified as acute injury rather than chronic neurodegeneration because the authors examined the changes in astrocyte transcriptome after an acute neurotoxic injury to the substantia nigra dopaminergic neurons (i.e., $12 \mathrm{~h}, 24 \mathrm{~h}$, and $48 \mathrm{~h}$ after a single MPTP intra-peritoneal injection), rather than after chronic MPTP administration through a subcutaneous osmotic pump [39]. Since the three acute MPTP time points are not independent datasets, only the $24 \mathrm{~h}$ dataset was used for the meta-analysis [15]. Mouse neurodegenerative datasets $(n=9)$ included ALS (various SOD1 mutants, $n=3$ ) [16-18] and AD models of both brain $\beta$-amyloidosis $(n=5)$ (APPswe/PSEN1deltaE9 $n=3$ and PS2APP $n=2$ ) [19-23], and tauopathy (P301SMAPT, $n=1$ ) [23]. Whenever more than one age group was available, only the older age group was analyzed.

\section{$A 1$ and $A 2$ astrocyte transcriptomic signatures are not CNS disease-specific}

Recently, an A1 neurotoxic signature and an A2 neuroprotective signature have been defined based on the DEGs from two acute injury mouse models: LPSinduced sepsis and MCAO stroke, respectively, with a third "pan-reactive" signature representing the common overlap between sepsis- and stroke-induced transcriptomic changes [1, 2]. Moreover, it has been suggested that, in neurodegenerative diseases, astrocytes also upregulate the A1 neurotoxic signature and downregulate

Table 2 Summary of publicly available human neurodegenerative transcriptomic datasets used in this study

\begin{tabular}{|c|c|c|c|c|c|c|c|}
\hline Label & Comparison & $\mathrm{N}$ & Sample type & RNA method & CNS region & Accession \# & Ref. \\
\hline AD-DLPC & $\begin{array}{l}\text { AD (Braak V/VI) vs } \\
\text { CTRL (Braak O/I/II) }\end{array}$ & $140 / 112$ & Bulk tissue & RNA-seq & $\begin{array}{l}\text { Dorsolateral } \\
\text { prefrontal cortex }\end{array}$ & syn3505720 & [32] \\
\hline AD-PHG & $\begin{array}{l}\text { AD (Braak V/VI) vs } \\
\text { CTRL (Braak 0/I/II) }\end{array}$ & $62 / 79$ & Bulk tissue & RNA-seq & $\begin{array}{l}\text { Parahippocampal } \\
\text { gyrus }\end{array}$ & syn5898488 & [33] \\
\hline AD-astro1 & $\begin{array}{l}\text { AD (Braak V/NI) vs } \\
\text { CTRL (Braak O/I/II) }\end{array}$ & $6 / 6$ & $\begin{array}{l}\text { LCM of GFAP+ } \\
\text { astrocytes }\end{array}$ & Microarray & $\begin{array}{l}\text { Lateral temporal } \\
\text { cortex }\end{array}$ & GDS4135 & [34] \\
\hline AD-astro2 & $\begin{array}{l}\text { AD (Braak V/NI) vs } \\
\text { CTRL (Braak 0/I/II) }\end{array}$ & $7 / 12$ & $\begin{array}{l}\text { FACS with } \\
\text { GFAP Ab }\end{array}$ & RNA-seq & $\begin{array}{l}\text { Superior frontal } \\
\text { gyrus }\end{array}$ & GSE125050 & $\begin{array}{l}\text { Friedman, } \\
\text { Hansen } \\
\text { (unpublished) }\end{array}$ \\
\hline PD-SN & PD vs CTRL & $3 / 3$ & Bulk tissue & Microarray & $\begin{array}{l}\text { Substantia } \\
\text { nigra }\end{array}$ & GSE54282 & [35] \\
\hline PD-Str & PD vs CTRL & $6 / 6$ & Bulk tissue & Microarray & Striatum & GSE54282 & [35] \\
\hline ALS-SC & SALS vs CTRL & $5 / 4$ & Bulk tissue & Microarray & $\begin{array}{l}\text { Spinal cord gray } \\
\text { matter }\end{array}$ & GSE833 & [36] \\
\hline
\end{tabular}

Abbreviations: $A b$ antibody, $A D$ Alzheimer's disease, $A L S$ amyotrophic lateral sclerosis, $C N S$ central nervous system, $C T R L$ control, $D L P C$ dorsolateral prefrontal cortex, FACS fluorescence-activated cell sorting, GFAP glial fibrillary acidic protein, LCM laser capture microdissection, PD Parkinson's disease, PHG parahippocampal gyrus, SALS sporadic ALS, SC spinal cord, SN substantia nigra, Str striatum 
the A2-neuroprotective signature [2]. To test the hypothesis that these $\mathrm{A} 1, \mathrm{~A} 2$, and pan-reactive signatures can be extrapolated to other acute injuries as well as neurodegenerative diseases, we examined the differential expression of the genes comprising these signatures in the 15 mouse datasets described above. The heatmaps in Fig. 1 show the fold change of the expression of the genes comprising these three signatures and the $p$ values of these comparisons. Surprisingly, overall the A1, A2, and pan-reactive genes were upregulated in astrocytes across most acute injury and neurodegeneration mouse models. Only MPTP appeared to induce a differential response, with an upregulation of the $\mathrm{A} 2$ and pan-reactive signatures and a downregulation of the A1 signature. Of note, astrocytes from acute injury mouse models tended to exhibit higher level of expression of all three gene cassettes than those from neurodegeneration mouse models. Overall, these analyses demonstrate that the previously described A1 and A2 signatures do not discern between CNS conditions and, in fact, are not mutually exclusive, but part of a broader pan-injury program that is common to both acute injury and chronic neurodegenerative responses.

\section{Meta-analysis of mouse astrocyte transcriptomic studies reveals distinct signatures of astrocyte reaction in acute CNS injuries versus chronic neurodegenerative diseases} Since the previously defined A1 and A2 signatures did not discriminate between injuries of very different nature, we next sought to describe new acute, chronic, and pan-injury astrocyte transcriptomic signatures. To this end, we conducted a meta-analysis of the DEGs, both upregulated (UP) and downregulated (DOWN), from the mouse acute and chronic datasets separately (Fig. 2a). We defined the pan-injury signature as genes with a statistically significant multiple-comparison-corrected

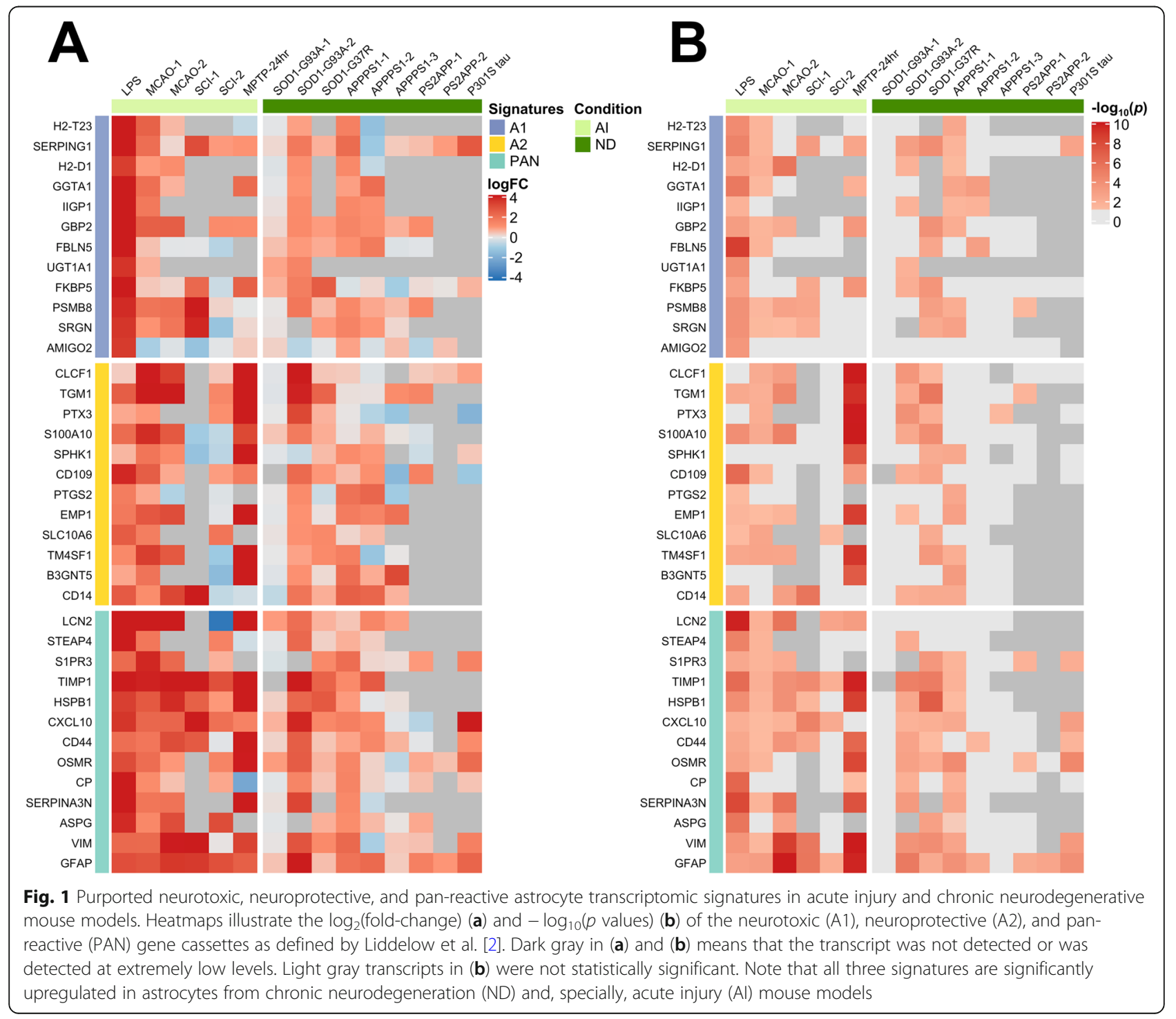




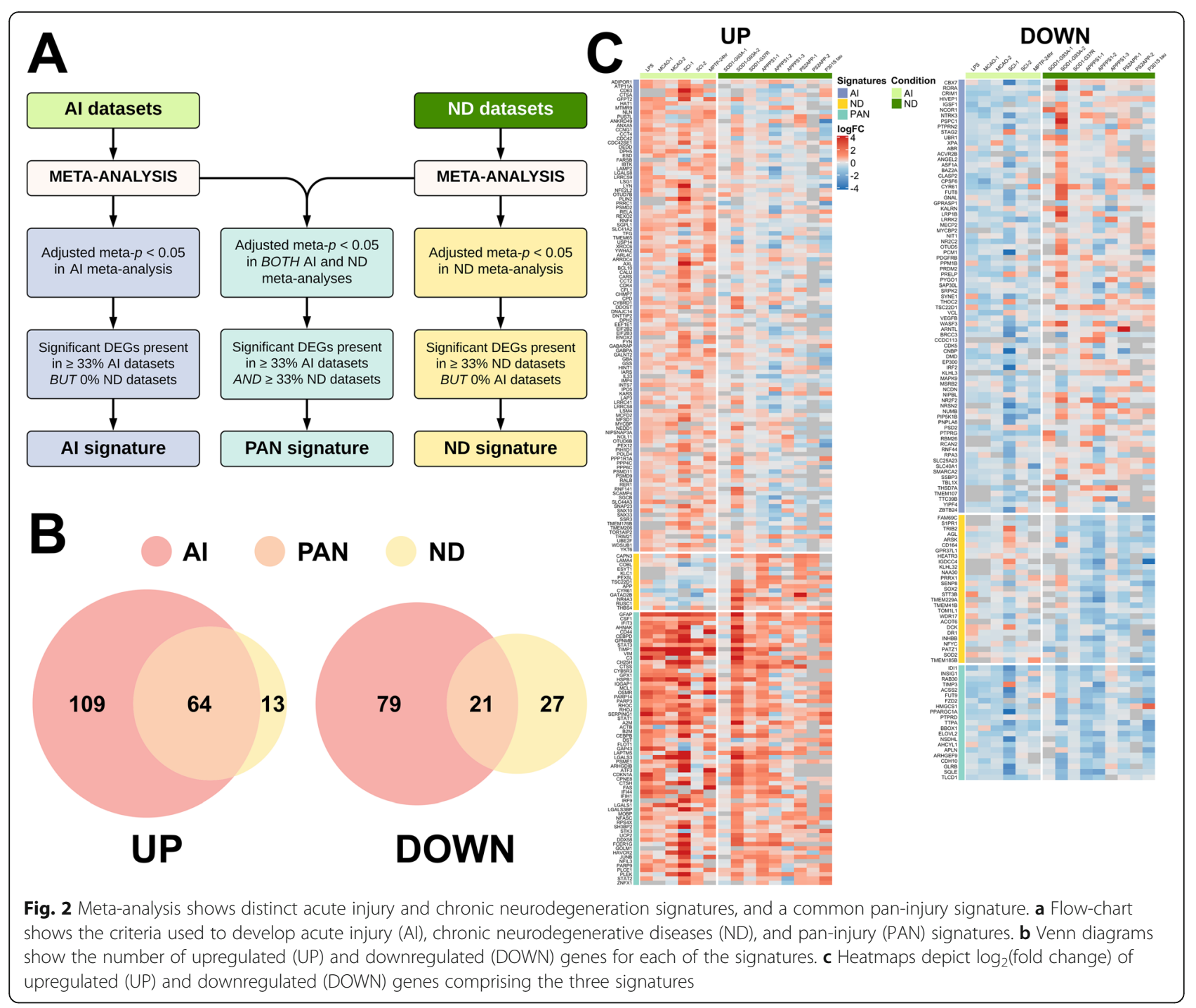

meta-analysis $p$ value $(p<0.05)$ in both acute and chronic datasets and which, as an additional filter, also reached statistical significance in at least $33 \%$ of both acute and chronic datasets (see the meta $p$ value of each signature gene and the number of acute and chronic datasets in which it was significant in Supplemental Table 1). The chronic neurodegeneration-specific signature was defined as DEGs that had an adjusted meta $p$ value $<0.05$ in the meta-analysis of chronic neurodegeneration datasets, were present in $33 \%$ or more of the neurodegeneration datasets, and absent in all acute injury datasets. Similarly, the acute injury-specific signature was defined by DEGs that had an adjusted meta $p$ value $<0.05$ in the meta-analysis of acute injury datasets, were present in $33 \%$ or more of all the acute injury datasets, and absent in all chronic neurodegeneration datasets.

Using these criteria, we obtained an acute injury-specific signature with 109 upregulated and 79 downregulated genes; a chronic neurodegeneration-specific signature with 13 upregulated and 27 downregulated genes, and a paninjury signature with 64 upregulated genes and 21 downregulated genes. The Venn diagrams in Fig. $2 \mathrm{~b}$ and the heatmaps in Fig. 2c and Supplemental Figure 1 depict the results of the meta-analysis for the UP and DOWN signatures, respectively. To characterize these signatures, we next interrogated curated databases such as Gene Ontology (GO biological processes, cellular components, and molecular functions) and Kyoto Encyclopedia of Genes and Genomes (KEGG) and generated heatmaps of relevant gene cassettes.

\section{Pan-injury astrocyte transcriptomic signature}

The pan-injury-UP signature corresponded to biological processes such as cytokine receptor and interferon signaling and to cellular components such as secretory vesicles, cell surface, and extracellular matrix. Specifically, this signature was represented by genes related to the cytoskeleton (Actb, 
Dst, Gfap, Vim), extracellular matrix (Cd44, Lgals1, Lgals3, Lgals3bp, Timp1), and immune response (C3, Csf1, Fas, Fcer1g, Havcr2, Ifi44, Ifih1, Ifit3, Irf9, Osmr, Serping1, Stat1, Stat2, Stat3), whereas the pan-injury-DOWN signature was comprised of genes with very diverse functions, although a lipid metabolism gene cassette (Acss2, Bbox1, Elovl2, Fzd2, Hmgcs1, Sqle) could be identified (Fig. 3).

\section{Acute injury-specific astrocyte transcriptomic signature}

The acute injury-UP signature corresponded to biological processes related to protein synthesis and degradation (proteasome and autophagy), response to cytokine and extracellular stimulus, and innate immune system, and to cell components such as endoplasmic reticulum, Golgi apparatus, and secretory granules and vesicles. Specifically, this signature includes gene cassettes related to protein synthesis (Calu, Cars, Dph2, Dph5, Eefle1, Eif2b2, Eif2b3, Farsb,
Iars, Kars), ER-Golgi trafficking (Ipo5, Lsg1, Nipsnap3a, Ralb, Rer1, Scamp4, Snap23, Snx10, Snx33, Ssr3, Ykt6), the ubiquitin-proteasome system (Cct2, Cct4, Dnajc14, Otud6b, Otud7b, Psmd2, Psmd9, Psmd11, Ube2f, Usp14), autophagy (Chmp7, Cpd, Ctsa, Cd63, Gba, Lamp2, Lap3), immune response (Bcl10, Fyn, Rela, Lgals8, Ppp6c), and anti-oxidant defense (Cybrd1, Enox2, Gss, Nfe2l2, Pex12) (Fig. 4). By contrast, the acute injury-DOWN signature was related to transcription and chromatin remodeling processes, localized to chromatin and cell nucleus, and was mainly comprised of genes that regulate chromatin structure and transcriptional activity (Arntl, Asf1a, Baz2a, Cbx7, Cnbp, Cpsf6, Ep300, Hivep1, Ncor1, Nipbl, Nr2c2, Nr2f2, Prdm2, Pspc1, Pygo1, Rnf44, Rora, Rpa3, Smarca2, Ssbp3, Stag2, $T s c 22 d 1, X p a$, and Zbtb24) (Fig. 5). Of note, many of these transcripts encode transcriptional repressors (i.e., $B a z 2 a$, Cbx7, Cnbp, Ncor1, Zbtb24), therefore their downregulation

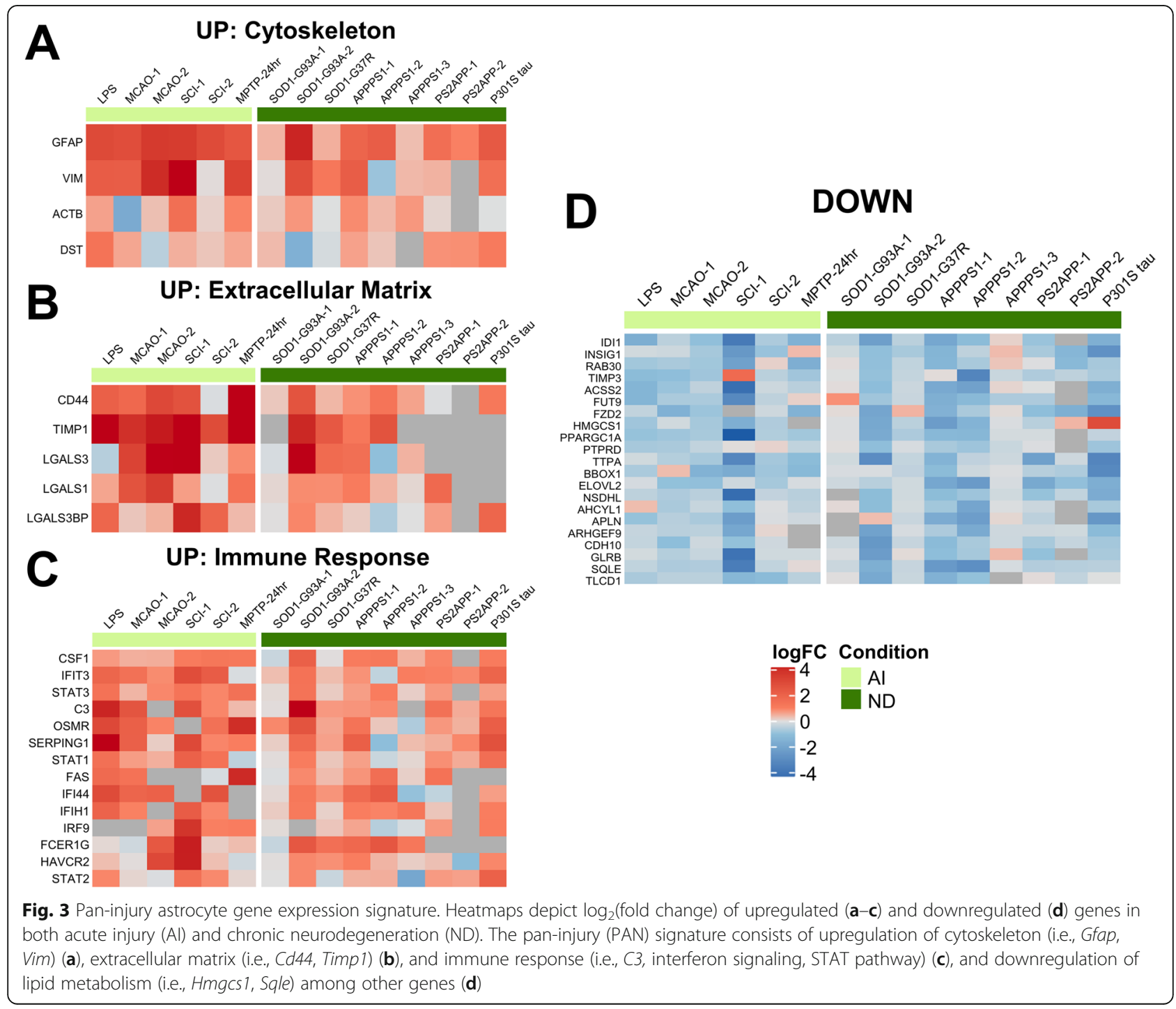




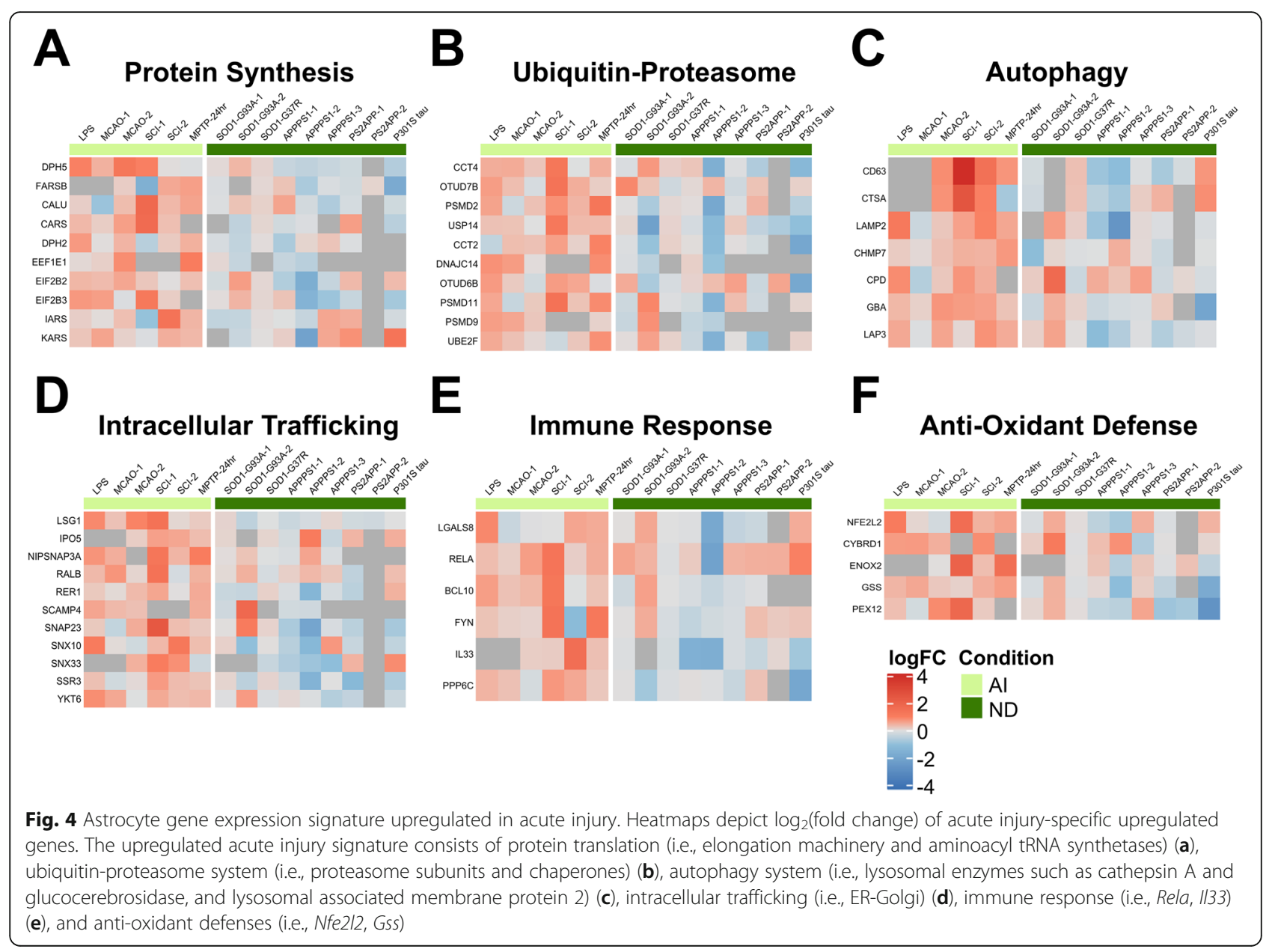

would lead to an enhanced transcriptional activity in the astrocytes. Other downregulated gene cassettes of interest in this signature included immune response (Igsf1, Irf2, Mapk9, Rcan2) and trophic factors (Acvr2b, Ntrk3, Pdgf3rb, Vegfb).

\section{Chronic neurodegeneration-specific astrocyte \\ transcriptomic signature}

The chronic neurodegeneration-specific signature was notably the smallest in number of genes, and these turned out to be functionally very heterogeneous. The chronic neurodegeneration-UP signature $(n=13)$ included three genes encoding extracellular matrix proteins that are known to be secreted by astrocytes (Cyr61, Lama4, and Thbs4). Other chronic neurodegenerationUP genes were App, Capn3, Cobl, Esyt1, Gatad2b, Klc1, Nr4a3, Pex5l, Rusc1, and Tsc22d1 (Fig. 6a). The chronic neurodegeneration-DOWN signature $(n=27)$ included a metabolic gene cassette (Acot6, Agl, Arsk, Naa30, $S t t 3 b)$ and a transcription/chromatin remodeling gene cassette (Dr1, Nfyc, Patz1, Prrxl) together with relevant genes such as Cd164, Heatr3, S1pr1, and Sod2 (Fig. 6b).
Astrocyte reaction involves upregulation of NFKB, MAPK, JAK-STAT, and CaN-NFAT signaling pathways, but not Wnt/ $\beta$-Catenin and Sonic hedgehog proliferative pathways

We next investigated which molecular signaling pathways are involved in astrocyte reaction in each condition and whether astrocyte proliferation is part of astrocyte reaction. Specifically, we hypothesized that acute CNS injuries would trigger astrocyte proliferation to create a scar and limit neuronal damage, whereas this proliferative potential of astrocytes could be exhausted in chronic neurodegenerative diseases. A literature review revealed four main signaling pathways involved in astrocyte reaction: nuclear factor kappa B (NFKB) [40], calcineurin-nuclear factor activating of T-cells (CaN-NFAT) [41-44], Janus Kinases/Signal Transducer and Activator of Transcription (JAK/STAT) [21, 45-47], and mitogen-activated protein kinase (MAPK) [34, 48-51], and two main pathways involved in astrocyte proliferation: $\mathrm{Wnt} / \beta$-catenin $[52,53]$ and Sonic hedgehog $[5,54]$.

To investigate whether these pathways are upregulated in reactive astrocytes in a context-dependent fashion, we performed GSEA [30] with the gene sets comprising these six pathways (see the "Methods" section) on the 6 


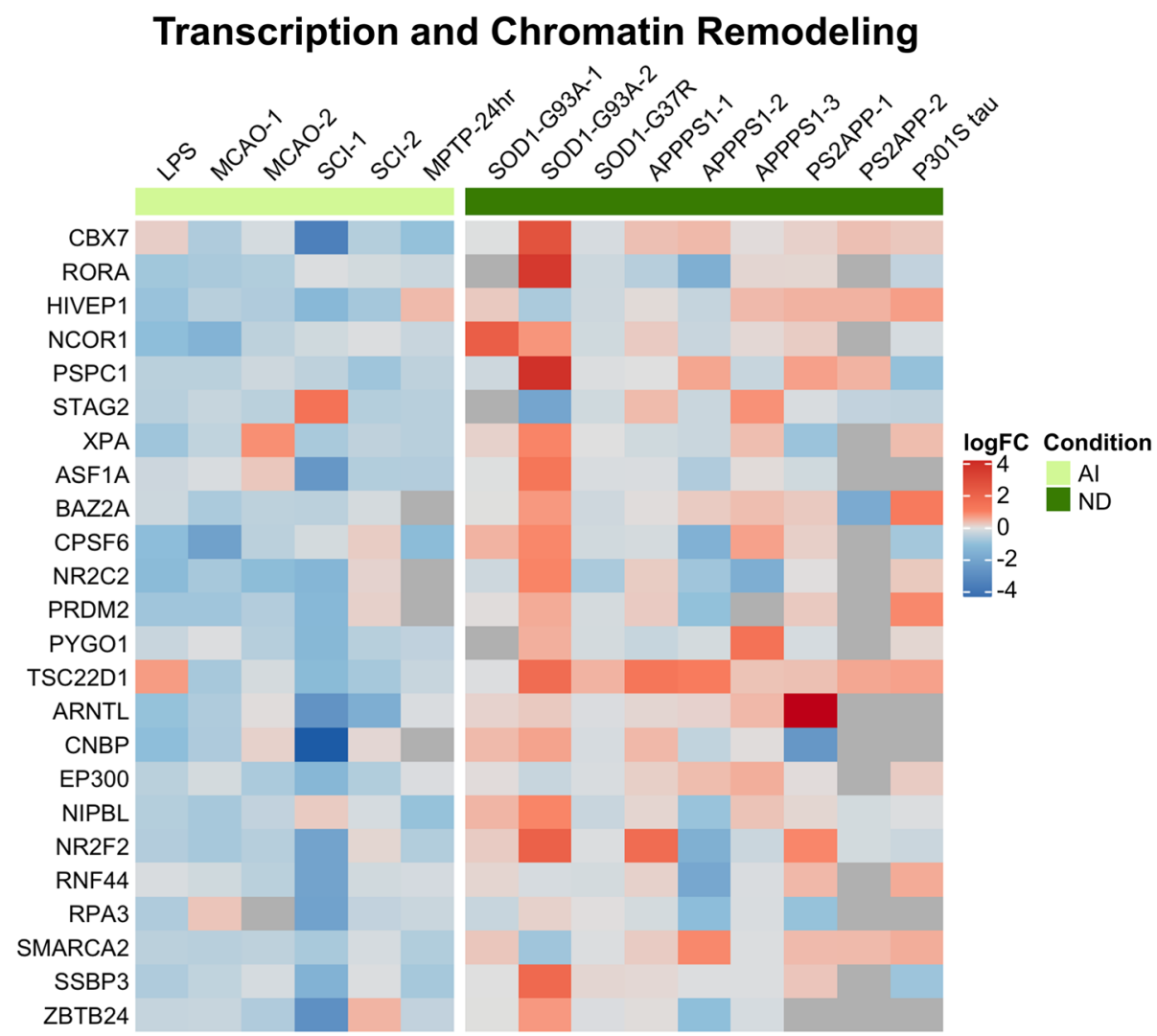

Fig. 5 Astrocyte gene expression signature downregulated in acute injury. Downregulated genes in acute injury were mainly related to chromatin remodeling and organization and transcription, including many transcriptional repressors

acute injury and 9 chronic neurodegeneration astrocyte transcriptomic datasets, followed by a meta-analysis of the resulting GSEA $p$ values. We identified a total of 86 gene sets related to one of these six signaling pathways with the following distribution: Wnt $/ \beta$-catenin $n=28$, MAPK $n=21, \operatorname{NFKB} n=19$, JAK/STAT $n=9$, NFAT $n$ $=6$, and Sonic hedgehog $n=3$. Figure 7 shows a heatmap with the NES resulting from the GSEA ranked by descending adjusted meta-analytic $p$ value, whereas Supplemental Figure 2 heatmap depicts the $-\log _{10}$ ( $p$ values) from this GSEA. The NFkB, JAK/STAT, and MAPK signaling pathways encompassed the top gene sets and were upregulated in most datasets from both acute injury and chronic neurodegeneration categories. By contrast, the $\mathrm{Wnt} / \beta$-catenin and Sonic hedgehog gene sets were predominantly downregulated and did not reach the meta-analytic statistical significance in most instances. Of note, the astrocyte pan-injury signature described above included Stat1, Stat2, and Stat3, whereas the acute injury-UP signature included Rela, which encodes for the effector subunit of NFKB p65, and the acute injury-DOWN signature included Rcan2, which is the main repressor of $\mathrm{Ca}-\mathrm{N} / \mathrm{NFAT}$ signaling, suggesting that the JAK/STAT signaling pathway is active in all astrocyte reactions, whereas $\mathrm{NF}_{\mathrm{K}} \mathrm{B}$ and NFAT signaling pathways are primarily turned on in response to acute injuries.

\section{Validation of mouse astrocyte signatures in human neurodegenerative diseases}

Lastly, we sought to validate the acute injury, chronic neurodegeneration, and pan-injury mouse astrocyte signatures in human brain transcriptomic (microarray and RNA-seq) datasets from neurodegenerative diseaserelevant $\mathrm{CNS}$ regions. These included two large $\mathrm{AD}$ datasets, the Religious Orders Study and Memory and Aging Project (ROSMAP, dorsolateral prefrontal cortex) [32] and the Mount Sinai Brain Bank (MSBB, parahippocampal gyrus) [33], two PD datasets (substantia nigra and striatum) [35], and one sporadic ALS dataset (spinal cord gray matter) [36]. In addition to these bulk tissue transcriptomic datasets, we analyzed two astrocytespecific AD datasets: one in which GFAP+ astrocytes were laser capture microdissected from lateral temporal cortex frozen sections [34], and another in which superior frontal gyrus astrocytes were labeled with a GFAP antibody and sorted from other cell types in the suspension through fluorescence-activated cell sorting (FACS) 

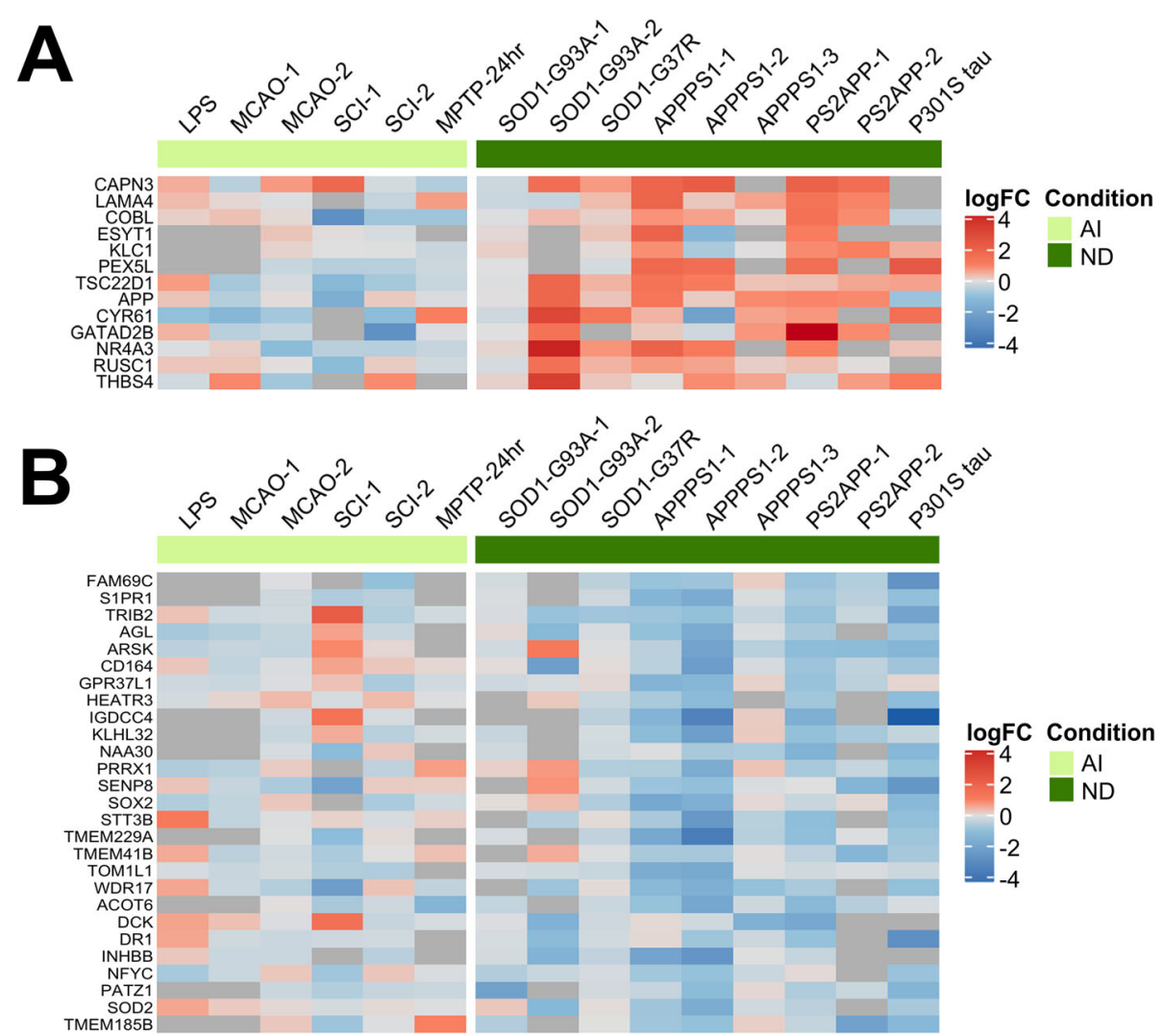

Fig. 6 Astrocyte gene expression signature in chronic neurodegeneration. The chronic neurodegeneration signature is characterized by upregulation (a) of amyloid precursor protein, calpain-3, and secreted matricellular proteins (i.e., Cyr61, Lama4, Thbs4), and downregulation (b) of metabolic processes (i.e., Acot6, Agl, Naa30)

(Friedman and Hansen, unpublished). Statistically significant DEGs $(p<0.05)$ between diseased and control individuals are illustrated with violin plots in Fig. 8, whereas violin plots with all the mouse signature genes are shown in Supplemental Figure 3. Inspection of these violin plots indicates that most genes from the paninjury-UP signature are also upregulated in the two $A D$ bulk tissue RNA-seq datasets from ROSMAP and MSBB. In contrast, the mouse chronic neurodegenerative-UP and all the DOWN signatures were not reflected in these large AD datasets. Similarly, none of the three mouse astrocyte signatures was clearly present in the two astrocyte-specific AD datasets, nor could they be validated in the two human PD and the ALS datasets.

\section{Discussion}

The main finding of this study is that, while sharing a common (pan-injury) astrocyte gene expression signature, mouse models of acute CNS injuries and neurodegenerative diseases are associated with very distinct astrocyte transcriptomic responses. On the one hand, astrocyte response to acute injury is remarkably characterized by an increased protein synthesis and degradation. Protein synthesis is unleashed by both upregulating the translational machinery of elongation factors (Eef1e1, Eif2b2, Eif2b3) and aminoacyl tRNA synthetases (Cars, Iars, Kars) and downregulating transcriptional repressors. Proteins involved in trafficking between the ER and the Golgi apparatus are also upregulated, likely reflecting the increasing demand for the folding, maturation, and intracellular transport of newly synthetized proteins. This massive protein synthesis is paralleled by an increased activity of protein degradation systems including the ubiquitin-proteasome system (i.e., upregulation of chaperones, ubiquitin ligases, and proteasome subunits) and autophagy (i.e., upregulation of lysosomal membrane proteins and enzymes), which probably serves the elimination of phagocytosed apoptotic and necrotic neurons from the injury area. In addition, the acute injury astrocyte signature consists of an immune response involving the upregulation of Rela (encoding for the $\mathrm{NFKB}$ effector subunit p65) and Il33 (encoding for interleukin-33) and the downregulation of Rcan2 (encoding for the regulator of calcineurin 2), among other genes. Of note, interleukin-33 is a nuclear alarmin expressed by astrocytes that induces microglial 


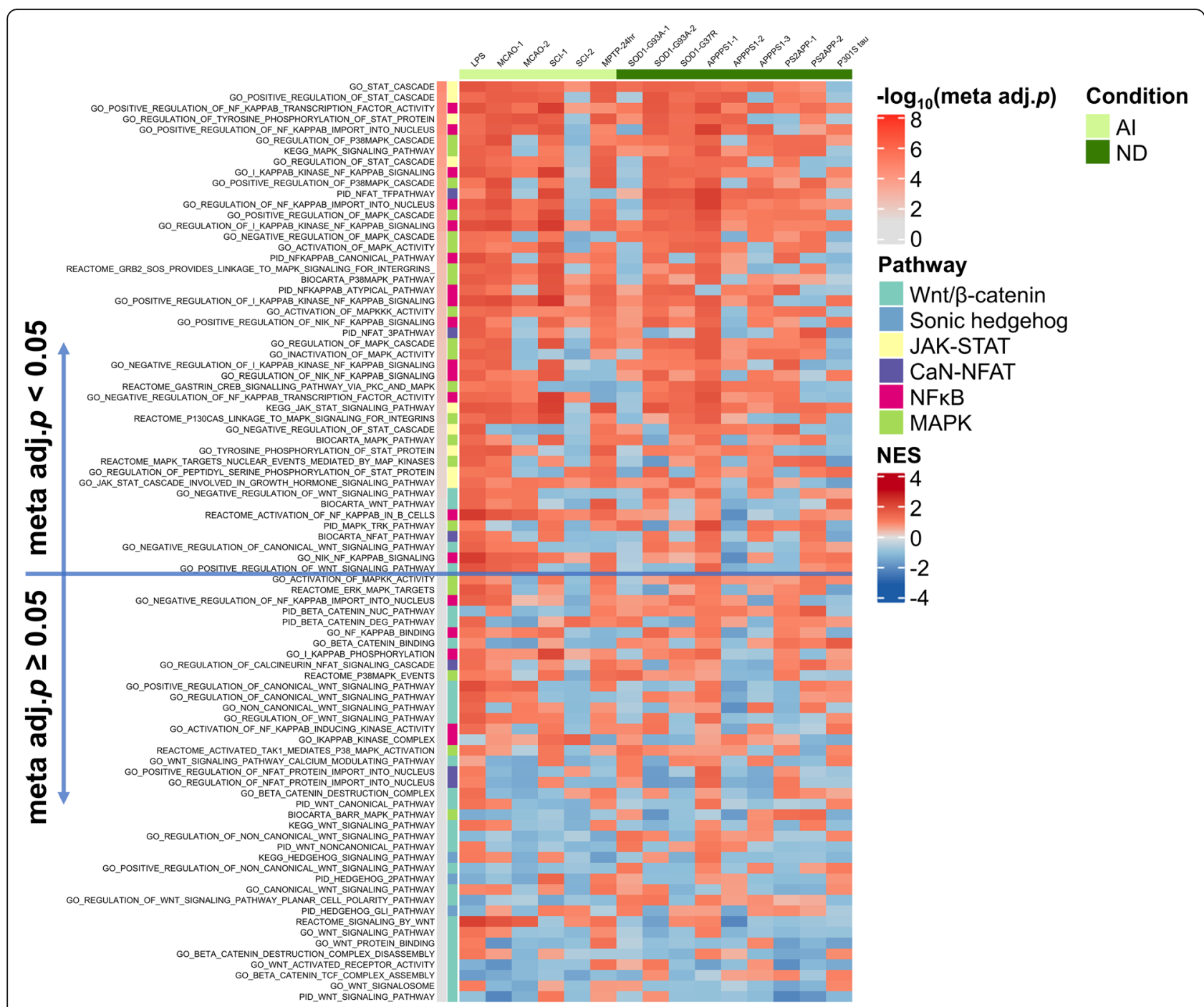

Fig. 7 Inflammatory but not proliferation signaling pathways are upregulated in acute injury and chronic neurodegeneration. Heatmap shows the normalized enrichment score (NES) of pro-inflammatory (NFKB, calcineurin/NFAT, MAPK, and JAK/STAT) and proliferative (Wnt/B-catenin and sonic hedgehog) gene sets in the astrocyte transcriptomic datasets analyzed. The gene sets are color-coded by pathway and ordered by descending meta-analytic $p$ value $[-\log 10($ Meta adj. $p)]$. Note that NFKB, MAPK, and JAK/STAT gene sets are more significantly upregulated than Wnt/ $\beta$ catenin and sonic hedgehog

engulfment of synapses during development [55, 56], and is neuroprotective in multiple models of acute CNS injury by shifting microglial phenotype towards a phagocytic one [57-62]. Lastly, the acute injury signature included an upregulation of anti-oxidant defenses exemplified by both $N f e 2 l 2$ (encoding the nuclear factor erythroid-derived 2-like 2 or NRF2), which is a major regulator of cellular anti-oxidant defenses and confers neuroprotection in acute CNS injuries [63-66] and neurodegenerative disease models [67, 68], and Gss, an NRF2 target gene encoding for the anti-oxidant enzyme glutathione synthetase.

In sharp contrast, the chronic reaction signature seen in neurodegenerative disease mouse models was much smaller, with the downregulated genes exceeding the number of upregulated ones. This could be partially explained by the fact that the median number of DEGs contributing to the meta-analysis was smaller for the chronic neurodegeneration datasets compared to acute injury datasets (UP, 823 vs 1402; DOWN, 775 vs 1468). An alternative explanation could be that our metaanalysis combined datasets obtained from very different models, CNS regions, and age groups, with disparate methodologies of astrocyte isolation or astrocyte RNA purification, and different transcriptomic methods (microarray versus RNA-seq). There are regional differences in mouse astrocyte transcriptome, and aging has been associated with region-specific transcriptomic 


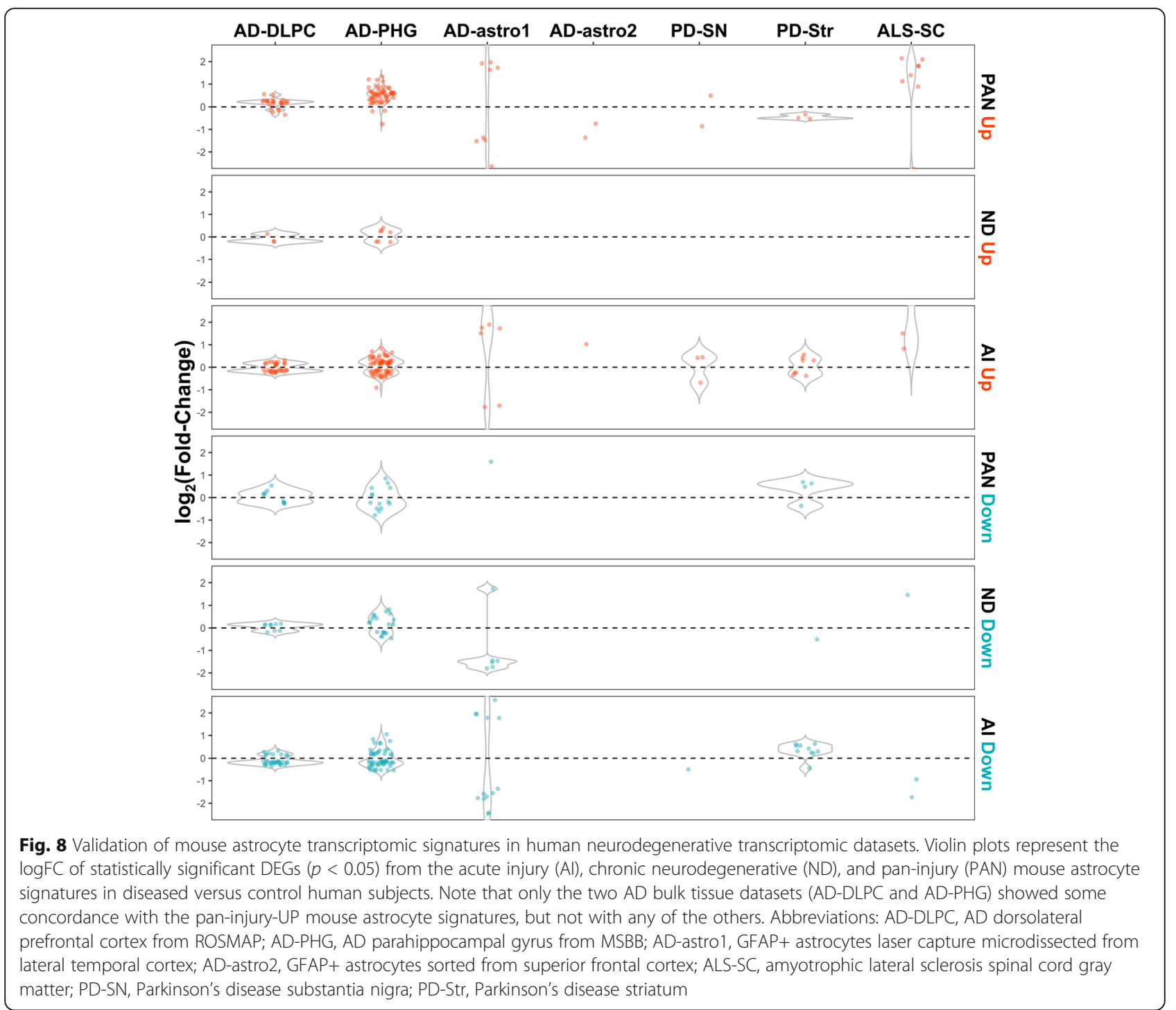

changes in mouse astrocytes [69-72]. Moreover, technological heterogeneity could be another contributor: for example, RNA-seq has several advantages over microarrays such as improved sensitivity, wider dynamic range, and the ability to detect novel and non-coding transcripts. This heterogeneity could have limited our ability to identify a common signature across disease mouse models and may have had a greater impact in the metaanalysis of chronic neurodegeneration datasets than in the meta-analysis of acute injury datasets. However, inspection of Table 1 reveals a similar degree of heterogeneity across acute injury and chronic neurodegeneration mouse studies, which did not preclude obtaining a sizable acute injury signature after meta-analysis. Thus, the findings of fewer DEGs in the chronic neurodegeneration datasets and a smaller chronic neurodegeneration signature compared to the acute injury datasets and signature, respectively, support the idea that mouse reactive astrocytes mount a less vigorous response in chronic relative to acute injuries.

A closer inspection of the list of chronic neurodegeneration-UP genes revealed that three of these genes are secreted extracellular matrix proteins: Cyr61 (CCN1 or cellular communication network factor 1), Lama4 (laminin $\alpha 4$ ), and Thbs4 (thrombospondin 4). Cyr61/CCN1 is a secreted matricellular protein that has been involved in cell-cell adhesion, angiogenesis, and arborization of dendrites of hippocampal neurons [73-76]. Immunohistochemical studies have revealed an upregulation of several laminins in reactive astrocytes in $A D$, Down's syndrome, and ALS [77-79]. Thrombospondins are astrocyte-secreted matricellular proteins involved in 
synaptogenesis $[80,81]$. Since $A \beta$ peptide can lead to synapse loss by inhibiting the secretion of thrombospondin 1 (TSP-1) by astrocytes [82, 83], and the P301S tauopathy mouse model exhibits decreased levels of TSP-1 in the brain [84], this upregulation of Thbs4 in neurodegenerative disease models could be compensatory to a decrease in TSP-1 levels. Three other transcripts upregulated in chronic neurodegeneration models encode for transcription factors: Gatad2b, Nr4a3, and Tsc22d1. Remarkably, GATA zinc finger domain containing 2B (GATAD2B) is a transcriptional repressor whose loss of function mutations have been associated with intellectual disability and synapse loss [85]. Nuclear receptor subfamily 4 group A member 3 has been involved in Lewy body disease and multiple system atrophy [86]. TSC22D1 is a pro-apoptotic tumor suppressor transcription factor induced by transforming growth factor $\beta$ (TGF $\beta$ ), that was found as putatively involved in $\mathrm{AD}$ pathophysiology in an unbiased network analysis of transcription factors and their targets [87] and was also present in our acute injury-DOWN signature. The presence of App (encoding the amyloid $\beta$ precursor protein or $\mathrm{A} \beta \mathrm{PP}$ ) in the neurodegeneration-UP signature is intriguing and cannot just be explained by a leakage of the $A P P$ transgene expression to astrocytes in $\mathrm{A} \beta \mathrm{PP}$-overexpressing $\mathrm{AD}$ mouse models [88], because it was also notably upregulated in other mouse models such as SOD1-G93A ALS mice. Increased A $\beta P P$ expression has been reported in reactive astrocytes under certain conditions, both in vitro [89] and in vivo [90-92].

Among the chronic neurodegeneration-DOWN genes, Agl, S1pr1, and Sod2 stand out. $\alpha$-Glycosidase (also called $\alpha$-amylase), encoded by $A g l$, is the rate-limiting enzyme of glycogenolysis and its downregulation in neurodegenerative mouse models implies an impairment of the energy supply to neurons through the astrocyteneuron lactate shuttle. However, while $A g l$ mRNA levels were found to be reduced in the hippocampal formation of $\mathrm{AD}$ patients compared to non-demented controls, an increased AGL immunoreactivity has been reported in $\mathrm{AD}$ reactive astrocytes [93, 94]. The sphingosine phosphate receptors 1 and 3 (S1PR1 and S1PR3) are upregulated by astrocytes in MS lesions [95-97], and their modulation by the FDA-approved MS drug and sphingosine analog fingolimod has beneficial anti-inflammatory and neurotrophic effects not only in MS but also in AD mouse models [98-101]. Deficiency of the anti-oxidant enzyme superoxide dismutase 2 (SOD2) in astrocytes leads to astrocyte oxidative stress [102], and a recent single nuclei RNA-seq study has found a downregulation of Sod2 in astrocytes from human AD brains [103]. On the other hand, post-mortem neuropathological studies have reported an enhanced SOD2 immunoreactivity in astrocytes in several neurodegenerative diseases such as ALS [104, 105] and FTLD-tau and TDP-43 [106], suggesting the existence of a mismatch either between mRNA and protein levels or between human disease and mouse models.

Besides these acute and chronic injury-specific signatures, our meta-analysis rendered a pan-injury signature with genes upregulated and downregulated in both types of CNS conditions. Our pan-injury-UP signature included 5 of the 13 genes proposed by Liddelow et al. as pan-reactive: Cd44, Gfap, Osmr, Timp1, and Vim. In addition, the putative A1 (neurotoxic) genes C3 and Serping1 were part of our pan-injury-UP signature [2]. Other pan-injury upregulated genes were Lgals1, Lgals3, and Lgals $3 b p$ encoding galectins 1 and 3 and galectin 3 binding protein, respectively. Astrocyte galectin-1 has been associated with worsening neurodegeneration of motor neurons in an ALS mouse model [107], but with neurotrophic and anti-inflammatory effects in models of MS [108] and brain ischemia $[109,110]$. The pan-injuryDOWN signature included genes involved in lipid metabolism (Acss2, Bbox1, Elovl2, Fzd2, Hmgcs1, Sqle), and other relevant genes such as Apln, Insig1, Ppargcla, and Ttpa. Apln encodes for apelin, a secreted peptide that has been shown to be neuroprotective in multiple acute injury and chronic neurodegenerative models [111-115]. Insig1 encodes for insulin induced gene 1 and its downregulation suggests a globally reduced insulin signaling [116]. Ppargc1a encodes for the peroxisome proliferator activator receptor $\gamma$ coactivator $1 \alpha$, and it is noteworthy that PPARy agonists have been proposed as antiinflammatory drugs for many CNS conditions [117]. Ttpa encodes for $\alpha$-tocopherol (vitamin E) transfer protein and, thus, has an anti-oxidant function; indeed, its deficiency leads to oxidative stress and enhanced $A \beta$ deposition in transgenic AD mice [118, 119].

While BrDU incorporation experiments and immunohistochemistry for proliferative markers (i.e., Ki67) are better suited to examine astrocyte proliferation in mouse models of CNS injury, our GSEA of relevant gene sets suggests that pro-inflammatory signaling pathways (JAK/ STAT, MAPK, NFKB, calcineurin/NFAT) are preponderant over proliferative signaling pathways (Wnt/ $\beta$-catenin and Sonic hedgehog) in both acute and chronic conditions, supporting the idea that astrocyte reaction represents mainly a phenotypic change of existing astrocytes rather than proliferation of glial progenitors $[8,120]$.

Finally, our exploratory validation of these mouse astrocyte signatures in human neurodegenerative transcriptomic datasets revealed little concordance, arguing for caution when extrapolating the findings of astrocyte mouse transcriptomic studies to the human disease scenario. These mouse versus human discrepancies can be explained by a combination of reasons: (1) there are inherent genomic, transcriptomic, and lifespan/aging differences between mice and humans [121]; (2) mouse 
models are unlikely to recapitulate the high degree of heterogeneity and complexity of human diseases; (3) most human transcriptomic datasets available were obtained from bulk tissue, which by definition dilutes the astrocyte transcripts among those from all the other cell types and reduces the sensitivity to detect astrocytespecific changes; (4) the isolation of astrocytes in the two human astrocyte-specific AD datasets was based on their GFAP immunoreactivity, likely biasing the astrocyte population towards a reactive phenotype in both $\mathrm{AD}$ and control individuals, and thus limiting the ability to find differences between both groups; and (5) there is a notable overlap in transcriptome between astrocytes and other cell types, singularly microglia. While recent single nuclei RNA-seq in AD and control human brains have produced quantitatively limited astrocyte datasets $[103,122,123]$, future astrocyte-enriched single nuclei RNA-seq studies from various human diseases will warrant a similar methodological approach and allow a more definite validation of the present findings from mouse models.

\section{Conclusions}

In summary, our meta-analysis of publicly available astrocyte transcriptomic datasets from multiple acute and chronic CNS injury mouse models highlights the heterogeneous nature of astrocyte reaction and provides important clues about its context dependence.

\section{Supplementary information}

Supplementary information accompanies this paper at https://doi.org/10. 1186/s12974-020-01898-y.

Additional file 1: Figure S1. Meta-analysis shows distinct acute injury and chronic neurodegeneration signatures, and a common pan-injury signature. Heatmaps depict - $\log _{10}(p$ value) of up-regulated (UP) and down-regulated (DOWN) genes comprising the acute injury (Al), chronic neurodegeneration (ND) and pan-injury (PAN) signatures.

Additional file 2: Figure S2. Inflammatory but not proliferation signaling pathways are up-regulated in acute injury and chronic neurodegeneration. Heatmap shows the $-\log _{10}(p$ value) of pro-inflammatory (NFKB, calcineurin/NFAT, MAPK, and JAK/STAT) and proliferative (Wnt/ $\beta$ catenin and sonic hedgehog) gene sets in the astrocyte transcriptomic datasets analyzed, corresponding to the GSEA in Figure 7. The gene sets are color-coded by pathway and ordered by descending meta-analytic $p$ value $[-\log 10$ (Meta adj. p)]. Note that NFKB, MAPK and JAK/STAT gene sets are statistically more significant than Wnt/ $\beta$-catenin and sonic hedgehog.

Additional file 3: Figure S3. Validation of mouse astrocyte transcriptomic signatures in human neurodegenerative transcriptomic datasets. Violin plots represent the logFC of all genes (both statistically significant and non-significant) from the acute injury (Al), chronic neurodegenerative (ND) and pan-injury (PAN) mouse astrocyte signatures in diseased versus control human subjects. Abbreviations: AD-DLPC $=A D$ dorsolateral prefrontal cortex from ROSMAP; AD-PHG = AD parahippocampal gyrus from MSBB; AD-astro1 = GFAP+ astrocytes laser capture microdissected from lateral temporal cortex; $\mathrm{AD}$-astro2 $=\mathrm{GFAP}+$ astrocytes sorted from superior frontal cortex; ALS-SC = amyotrophic lateral sclerosis spinal cord gray matter; PD-SN = Parkinson's disease substantia nigra; PDStr $=$ Parkinson's disease striatum.

\section{Additional file 4: Table S1.}

\section{Abbreviations}

Ab: Antibody; A 3 : Amyloid $\beta$ peptide; A $\beta P P$ : Amyloid- $\beta$ precursor protein; AD: Alzheimer's disease; Al: Acute injury; Aldh1L1: Aldehyde dehydrogenase 1 L1; AGL: a-Glycosidase; ALS: Amyotrophic lateral sclerosis; CA1: Cornus ammonis 1; CaN-NFAT: Calcineurin-nuclear factor activating of T-cells; cc: Corpus callosum; CCN1: Cellular communication network factor 1; CNS: Central nervous system; CTRL: Control; ctx: Cortex; Cx43: Connexin-43; DEGs: Differentially expressed genes; DLPC: Dorsolateral prefrontal cortex; DOWN: Downregulated; eGFP: Enhanced green fluorescent protein; ER: Endoplasmic reticulum; FACS: Fluorescence-activated cell sorting; FDA: Food and Drug Administration; FDR: False discovery rate; FKPM: Fragments per kilobase of transcript per million mapped reads; FTLD: Frontotemporal lobar degeneration; GATAD2B: GATA zinc finger domain containing 2B; GFAP: Glial fibrillary acidic protein; Glt1: Glutamate transporter 1; GO: Gene Ontology; GSEA: Gene set enrichment analysis; i.p.: Intra-peritoneal; JAK/STAT: Janus Kinases/Signal Transducer and Activator of Transcription; KEGG: Kyoto Encyclopedia of Genes and Genomes; LCM: Laser capture microdissection; logFC: Logarithm of fold-change; LPS: Lipopolysaccharide; MAPK: Mitogen-activated protein kinase; MAPT: Microtubule-associated protein tau; MCAO: Middle cerebral artery occlusion; MPTP: 1-Methyl-4-phenyl-1,2,3,6-tetrahydropyridine; MS: Multiple sclerosis; MSBB: Mount Sinai Brain Bank; ND: Neurodegeneration; NES: Normalized enrichment score; NFkB: Nuclear factor kappa B; NFT: Neurofibrillary tangle; NRF2: Nuclear factor erythroid-derived 2-like 2; PAN: Pan-injury; PD: Parkinson's disease; PHG: Parahippocampal gyrus; PPARY: Peroxisome proliferator activator receptor Y; PS1/2: Presenilin 1/2; RNA-seq: Ribonucleic acid sequencing; ROSMAP: Religious Orders Study and Memory and Aging Project; S1PR1/3: Sphingosine phosphate receptors 1/3; sac: Sacrifice; SALS: Sporadic ALS; SC: Spinal cord; SCl: Spinal cord injury; SN: Substantia nigra; SOD1/2: Superoxide dismutase 1/2; Str: Striatum; TBI: Traumatic brain injury; TDP-43: Tar DNA-binding protein $43 \mathrm{kDa}$; TGF $\beta$ : Transforming growth factor $\beta$; TRAP: Translating ribosome affinity purification; TSP-1: Thrombospondin 1; UP: Upregulated

\section{Acknowledgements}

Not applicable

\section{Authors' contributions}

SD designed the analyses, analyzed some of the data, interpreted the results, and edited the manuscript. ZL wrote the R code and analyzed most of the data. AN analyzed some of the data. BTH provided intellectual input and edited the manuscript. AS-P conceived the idea, designed the analyses, interpreted the results, and wrote the manuscript. All authors read and approved the final manuscript.

\section{Funding}

This work was supported by a grant from the Alzheimer's Association (AACF-17-524184 to AS-P) and grants from the National Institute on Aging (1K08AG064039 to AS-P and P30AG062421 to SD/BTH). The ROSMAP project was supported by funding from the National Institute on Aging (AG034504 and AG041232). The MSBB data were generated from post-mortem brain tissue collected through the Mount Sinai VA Medical Center Brain Bank and were provided by Dr. Eric Schadt from Mount Sinai School of Medicine.

\section{Availability of data and materials}

The datasets used and/or analyzed during the current study are available from the corresponding author on reasonable request.

Ethics approval and consent to participate Not applicable.

\section{Consent for publication}

Not applicable.

Competing interests

The authors declare that they have no competing interests. 


\section{Author details}

'MGH BioMedical Informatics Core (BMIC), Cambridge, MA 02139, USA. ${ }^{2}$ Department of Neurology, Massachusetts General Hospital, Boston, MA 02114, USA. ${ }^{3}$ Massachusetts Alzheimer's Disease Research Center, 114 16th street, Suite 2012, Charlestown, MA 02129, USA. ${ }^{4}$ Harvard Medical School, Boston, MA 02116, USA.

\section{Received: 31 March 2020 Accepted: 15 July 2020}

\section{Published online: 31 July 2020}

\section{References}

1. Zamanian JL, Xu L, Foo LC, Nouri N, Zhou L, Giffard RG, et al. Genomic analysis of reactive astrogliosis. J Neurosci Off J Soc Neurosci. 2012;32(18): 6391-410.

2. Liddelow SA, Guttenplan KA, Clarke LE, Bennett FC, Bohlen CJ, Schirmer L, et al. Neurotoxic reactive astrocytes are induced by activated microglia. Nature. 2017:541(7638):481-7.

3. Buffo A, Rite I, Tripathi P, Lepier A, Colak D, Horn A-P, et al. Origin and progeny of reactive gliosis: a source of multipotent cells in the injured brain. Proc Natl Acad Sci U S A. 2008:105(9):3581-6.

4. Bardehle S, Krüger M, Buggenthin F, Schwausch J, Ninkovic J, Clevers H, et al. Live imaging of astrocyte responses to acute injury reveals selective juxtavascular proliferation. Nat Neurosci. 2013;16(5):580-6.

5. Sirko S, Behrendt G, Johansson PA, Tripathi P, Costa M, Bek S, et al. Reactive glia in the injured brain acquire stem cell properties in response to sonic hedgehog. [corrected]. Cell Stem Cell. 2013;12(4):426-39.

6. Bondolfi L, Calhoun M, Ermini F, Kuhn HG, Wiederhold K-H, Walker L, et al. Amyloid-associated neuron loss and gliogenesis in the neocortex of amyloid precursor protein transgenic mice. J Neurosci Off J Soc Neurosci. 2002:22(2):515-22.

7. Kamphuis W, Orre M, Kooijman L, Dahmen M, Hol EM. Differential cell proliferation in the cortex of the APPSwePS1dE9 Alzheimer's disease mouse model. Glia. 2012 Apr:60(4):615-29.

8. Serrano-Pozo A, Gómez-Isla T, Growdon JH, Frosch MP, Hyman BT. A phenotypic change but not proliferation underlies glial responses in Alzheimer disease. Am J Pathol. 2013;182(6):2332-44.

9. Lepore AC, Dejea C, Carmen J, Rauck B, Kerr DA, Sofroniew MV, et al. Selective ablation of proliferating astrocytes does not affect disease outcome in either acute or chronic models of motor neuron degeneration. Exp Neurol. 2008;211(2):423-32.

10. R Core Team. R: a language and environment for statistical computing. $R$ Found Stat Comput. 2018; Available from: https://www.R-project.org/.

11. Gene Expression Omnibus. [cited 2020 Jan 12]; Available from: https://www. ncbi.nlm.nih.gov/geo/.

12. Rakers C, Schleif M, Blank N, Matušková H, Ulas T, Händler K, et al. Stroke target identification guided by astrocyte transcriptome analysis. Glia. 2019; 67(4):619-33.

13. Anderson MA, Burda JE, Ren $Y$, Ao Y, O'Shea TM, Kawaguchi R, et al. Astrocyte scar formation aids central nervous system axon regeneration. Nature. 2016:532(7598):195-200.

14. Noristani HN, Sabourin JC, Boukhaddaoui H, Chan-Seng E, Gerber YN, Perrin FE. Spinal cord injury induces astroglial conversion towards neuronal lineage. Mol Neurodegener. 2016;11(1):68

15. Michalovicz LT, Kelly KA, Vashishtha S, Ben-Hamo R, Efroni S, Miller JV, et al. Astrocyte-specific transcriptome analysis using the ALDH1L1 bacTRAP mouse reveals novel biomarkers of astrogliosis in response to neurotoxicity. J Neurochem. 2019;150(4):420-40.

16. Miller SJ, Glatzer JC, Hsieh Y-C, Rothstein JD. Cortical astroglia undergo transcriptomic dysregulation in the G93A SOD1 ALS mouse model. J Neurogenet. 2018;32(4):322-35

17. Baker DJ, Blackburn DJ, Keatinge M, Sokhi D, Viskaitis P, Heath PR, et al. Lysosomal and phagocytic activity is increased in astrocytes during disease progression in the SOD1 (G93A) mouse model of amyotrophic lateral sclerosis. Front Cell Neurosci. 2015:9:410.

18. Sun S, Sun Y, Ling S-C, Ferraiuolo L, McAlonis-Downes M, Zou Y, et al. Translational profiling identifies a cascade of damage initiated in motor neurons and spreading to glia in mutant SOD1-mediated ALS. Proc Natl Acad Sci U S A. 2015;112(50):E6993-7002.

19. Orre M, Kamphuis W, Osborn LM, Jansen AHP, Kooijman L, Bossers $K$, et al. Isolation of glia from Alzheimer's mice reveals inflammation and dysfunction. Neurobiol Aging. 2014;35(12):2746-60.
20. Kamphuis W, Kooijman L, Orre M, Stassen O, Pekny M, Hol EM. GFAP and vimentin deficiency alters gene expression in astrocytes and microglia in wild-type mice and changes the transcriptional response of reactive glia in mouse model for Alzheimer's disease. Glia. 2015;63(6):1036-56.

21. Ceyzériat K, Ben Haim L, Denizot A, Pommier D, Matos M, Guillemaud O, et al. Modulation of astrocyte reactivity improves functional deficits in mouse models of Alzheimer's disease. Acta Neuropathol Commun. 2018; 6(1):104.

22. Srinivasan K, Friedman BA, Larson JL, Lauffer BE, Goldstein LD, Appling LL, et al. Untangling the brain's neuroinflammatory and neurodegenerative transcriptional responses. Nat Commun. 2016;7:11295.

23. Wu T, Dejanovic B, Gandham VD, Gogineni A, Edmonds R, Schauer $S$, et al. Complement $\mathrm{C} 3$ is activated in human $\mathrm{AD}$ brain and is required for neurodegeneration in mouse models of amyloidosis and tauopathy. Cell Rep. 2019:28(8):2111-2123.e6.

24. Patro R, Duggal G, Love MI, Irizarry RA, Kingsford C. Salmon provides fast and bias-aware quantification of transcript expression. Nat Methods. 2017; 14(4):417-9.

25. Ritchie ME, Phipson B, Wu D, Hu Y, Law CW, Shi W, et al. limma powers differential expression analyses for RNA-sequencing and microarray studies. Nucleic Acids Res. 2015;43(7):e47.

26. Law CW, Chen Y, Shi W, Smyth GK. voom: precision weights unlock linear model analysis tools for RNA-seq read counts. Genome Biol. 2014;15(2):R29.

27. Dewey M. Metap: meta-analysis of significance values. R Package Version 11; 2019.

28. Zhang Y, Chen K, Sloan SA, Bennett ML, Scholze AR, O'Keeffe S, et al. An RNA-sequencing transcriptome and splicing database of glia, neurons, and vascular cells of the cerebral cortex. J Neurosci Off J Soc Neurosci. 2014; 34(36):11929-47.

29. Liberzon A, Birger C, Thorvaldsdóttir H, Ghandi M, Mesirov JP, Tamayo P. The Molecular Signatures Database (MSigDB) hallmark gene set collection. Cell Syst. 2015;1(6):417-25.

30. Subramanian A, Tamayo P, Mootha VK, Mukherjee S, Ebert BL, Gillette MA et al. Gene set enrichment analysis: a knowledge-based approach for interpreting genome-wide expression profiles. Proc Natl Acad Sci U S A. 2005:102(43):15545-50

31. Gene Set Enrichment Analysis. [cited 2019 Dec 17]; Available from: http:// software.broadinstitute.org/gsea/index.jsp.

32. De Jager PL, Ma Y, McCabe C, Xu J, Vardarajan BN, Felsky D, et al. A multiomic atlas of the human frontal cortex for aging and Alzheimer's disease research. Sci Data. 2018:5:180142.

33. Wang M, Beckmann ND, Roussos P, Wang E, Zhou X, Wang Q, et al. The Mount Sinai cohort of large-scale genomic, transcriptomic and proteomic data in Alzheimer's disease. Sci Data. 2018;5:180185.

34. Simpson JE, Ince PG, Shaw PJ, Heath PR, Raman R, Garwood CJ, et al. Microarray analysis of the astrocyte transcriptome in the aging brain: relationship to Alzheimer's pathology and APOE genotype. Neurobiol Aging. 2011;32(10):1795-807.

35. Riley BE, Gardai SJ, Emig-Agius D, Bessarabova M, Ivliev AE, Schüle B, et al. Systems-based analyses of brain regions functionally impacted in Parkinson's disease reveals underlying causal mechanisms. PloS One. 2014, 9(8):e102909.

36. Dangond F, Hwang D, Camelo S, Pasinelli P, Frosch MP, Stephanopoulos G, et al. Molecular signature of late-stage human ALS revealed by expression profiling of postmortem spinal cord gray matter. Physiol Genomics. 2004; 16(2):229-39.

37. Bihlmeyer NA, Merrill E, Lambert $Y$, Srivastava GP, Clark TW, Hyman BT, et al. Novel methods for integration and visualization of genomics and genetics data in Alzheimer's disease. Alzheimers Dement J Alzheimers Assoc. 2019; 15(6):788-98.

38. Wickham H. ggplot2: elegant graphics for data analysis. New York: SpringerVerlag; 2016.

39. Muñoz-Manchado AB, Villadiego J, Suárez-Luna N, Bermejo-Navas A, Garrido-Gil P, Labandeira-García JL, et al. Neuroprotective and reparative effects of carotid body grafts in a chronic MPTP model of Parkinson's disease. Neurobiol Aging. 2013;34(3):902-15.

40. Ouali Alami N, Schurr C, Olde Heuvel F, Tang L, Li Q, Tasdogan A, et al. NF$\mathrm{KB}$ activation in astrocytes drives a stage-specific beneficial neuroimmunological response in ALS. EMBO J. 2018;15:37(16).

41. Norris CM, Kadish I, Blalock EM, Chen K-C, Thibault V, Porter NM, et al. Calcineurin triggers reactive/inflammatory processes in astrocytes and is 
upregulated in aging and Alzheimer's models. J Neurosci Off J Soc Neurosci. 2005;25(18):4649-58.

42. Abdul HM, Sama MA, Furman JL, Mathis DM, Beckett TL, Weidner AM, et al. Cognitive decline in Alzheimer's disease is associated with selective changes in calcineurin/NFAT signaling. J Neurosci Off J Soc Neurosci. 2009; 29(41):12957-69.

43. Furman JL, Sama DM, Gant JC, Beckett TL, Murphy MP, Bachstetter AD, et al. Targeting astrocytes ameliorates neurologic changes in a mouse model of Alzheimer's disease. J Neurosci Off J Soc Neurosci. 2012;32(46):16129-40.

44. Sompol P, Furman $J$, Pleiss MM, Kraner SD, Artiushin IA, Batten SR, et al. Calcineurin/NFAT signaling in activated astrocytes drives network hyperexcitability in Aß-bearing mice. J Neurosci Off J Soc Neurosci. 2017; 37(25):6132-48

45. Sriram K, Benkovic SA, Hebert MA, Miller DB, O'Callaghan JP. Induction of gp130-related cytokines and activation of JAK2/STAT3 pathway in astrocytes precedes up-regulation of glial fibrillary acidic protein in the 1-methyl-4phenyl-1,2,3,6-tetrahydropyridine model of neurodegeneration: key signaling pathway for astrogliosis in vivo? J Biol Chem. 2004;279(19):19936-47.

46. Ben Haim L, Ceyzériat K, Carrillo-de Sauvage MA, Aubry F, Auregan G, Guillermier M, et al. The JAK/STAT3 pathway is a common inducer of astrocyte reactivity in Alzheimer's and Huntington's diseases. J Neurosci Off J Soc Neurosci. 2015;35(6):2817-29.

47. Levine J, Kwon E, Paez P, Yan W, Czerwieniec G, Loo JA, et al. Traumatically injured astrocytes release a proteomic signature modulated by STAT3dependent cell survival. Glia. 2016;64(5):668-94.

48. Hyman BT, Elvhage TE, Reiter J. Extracellular signal regulated kinases. Localization of protein and mRNA in the human hippocampal formation in Alzheimer's disease. Am J Pathol. 1994;144(3):565-72.

49. Mandell JW, VandenBerg SR. ERK/MAP kinase is chronically activated in human reactive astrocytes. Neuroreport. 1999;10(17):3567-72.

50. Cole-Edwards KK, Musto AE, Bazan NG. c-Jun N-terminal kinase activation responses induced by hippocampal kindling are mediated by reactive astrocytes. J Neurosci Off J Soc Neurosci. 2006;26(32):8295-304.

51. McCoy E, Sontheimer H. MAPK induces AQP1 expression in astrocytes following injury. Glia. 2010;58(2):209-17.

52. White BD, Nathe RJ, Maris DO, Nguyen NK, Goodson JM, Moon RT, et al. Beta-catenin signaling increases in proliferating NG2+ progenitors and astrocytes during post-traumatic gliogenesis in the adult brain. Stem Cells Dayt Ohio. 2010;28(2):297-307.

53. L'Episcopo F, Tirolo C, Testa N, Caniglia S, Morale MC, Cossetti C, et al. Reactive astrocytes and $\mathrm{Wnt} / \beta$-catenin signaling link nigrostriatal injury to repair in 1-methyl-4-phenyl-1,2,3,6-tetrahydropyridine model of Parkinson's disease. Neurobiol Dis. 2011;41(2):508-27.

54. Amankulor NM, Hambardzumyan D, Pyonteck SM, Becher OJ, Joyce JA, Holland EC. Sonic hedgehog pathway activation is induced by acute brain injury and regulated by injury-related inflammation. J Neurosci Off J Soc Neurosci. 2009;29(33):10299-308.

55. Wicher G, Husic E, Nilsson G, Forsberg-Nilsson K. Developmental expression of IL-33 in the mouse brain. Neurosci Lett. 2013;555:171-6.

56. Vainchtein ID, Chin G, Cho FS, Kelley KW, Miller JG, Chien EC, et al. Astrocyte-derived interleukin-33 promotes microglial synapse engulfment and neural circuit development. Science. 2018;359(6381):1269-73.

57. Gadani SP, Walsh JT, Smirnov I, Zheng J, Kipnis J. The glia-derived alarmin IL-33 orchestrates the immune response and promotes recovery following CNS injury. Neuron. 2015;85(4):703-9.

58. Chen H, Sun Y, Lai L, Wu H, Xiao Y, Ming B, et al. Interleukin-33 is released in spinal cord and suppresses experimental autoimmune encephalomyelitis in mice. Neuroscience. 2015;308:157-68.

59. Pomeshchik Y, Kidin I, Korhonen P, Savchenko E, Jaronen M, Lehtonen S, et al. Interleukin-33 treatment reduces secondary injury and improves functional recovery after contusion spinal cord injury. Brain Behav Immun. 2015:44:68-81.

60. Yang Y, Liu H, Zhang H, Ye Q, Wang J, Yang B, et al. ST2/IL-33-dependent microglial response limits acute ischemic brain injury. J Neurosci Off J Soc Neurosci. 2017;37(18):4692-704.

61. Gao Y, Luo C-L, Li L-L, Ye G-H, Gao C, Wang H-C, et al. IL-33 provides neuroprotection through suppressing apoptotic, autophagic and NF-KBmediated inflammatory pathways in a rat model of recurrent neonatal seizure. Front Mol Neurosci. 2017;10:423.

62. Chen Z, Xu N, Dai X, Zhao C, Wu X, Shankar S, et al. Interleukin-33 reduces neuronal damage and white matter injury via selective microglia M2 polarization after intracerebral hemorrhage in rats. Brain Res Bull. 2019;150: 127-35.

63. Chen P-C, Vargas MR, Pani AK, Smeyne RJ, Johnson DA, Kan YW, et al. Nrf2mediated neuroprotection in the MPTP mouse model of Parkinson's disease: critical role for the astrocyte. Proc Natl Acad Sci U S A. 2009;106(8): 2933-8.

64. Bell KF, Al-Mubarak B, Fowler JH, Baxter PS, Gupta K, Tsujita T, et al. Mild oxidative stress activates Nrf2 in astrocytes, which contributes to neuroprotective ischemic preconditioning. Proc Natl Acad Sci U S A. 2011; 108(1):E1 -2-4.

65. Xu J, Huang G, Zhang K, Sun J, Xu T, Li R, et al. Nrf2 activation in astrocytes contributes to spinal cord ischemic tolerance induced by hyperbaric oxygen preconditioning. J Neurotrauma. 2014;31(15):1343-53.

66. Draheim T, Liessem A, Scheld M, Wilms F, Weißflog M, Denecke B, et al. Activation of the astrocytic Nrf2/ARE system ameliorates the formation of demyelinating lesions in a multiple sclerosis animal model. Glia. 2016;64(12): 2219-30.

67. Vargas MR, Johnson DA, Sirkis DW, Messing A, Johnson JA. Nrf2 activation in astrocytes protects against neurodegeneration in mouse models of familial amyotrophic lateral sclerosis. J Neurosci Off J Soc Neurosci. 2008;28(50): 13574-81.

68. Lastres-Becker I, Ulusoy A, Innamorato NG, Sahin G, Rábano A, Kirik D, et al. a-Synuclein expression and Nrf2 deficiency cooperate to aggravate protein aggregation, neuronal death and inflammation in early-stage Parkinson's disease. Hum Mol Genet. 2012;21(14):3173-92.

69. John Lin C-C, Yu K, Hatcher A, Huang T-W, Lee HK, Carlson J, et al. Identification of diverse astrocyte populations and their malignant analogs. Nat Neurosci. 2017;20(3):396-405

70. Chai H, Diaz-Castro B, Shigetomi E, Monte E, Octeau JC, Yu X, et al. Neural circuit-specialized astrocytes: transcriptomic, proteomic, morphological, and functional evidence. Neuron. 2017;95(3):531-549.e9.

71. Clarke LE, Liddelow SA, Chakraborty C, Münch AE, Heiman M, Barres BA. Normal aging induces A1-like astrocyte reactivity. Proc Natl Acad Sci U S A. 2018;115(8):E1896-905.

72. Boisvert MM, Erikson GA, Shokhirev MN, Allen NJ. The aging astrocyte transcriptome from multiple regions of the mouse brain. Cell Rep. 2018; 22(1):269-85.

73. Malik AR, Urbanska M, Gozdz A, Swiech LJ, Nagalski A, Perycz M, et al. Cyr61, a matricellular protein, is needed for dendritic arborization of hippocampal neurons. J Biol Chem. 2013;288(12):8544-59.

74. Jones EV, Bouvier DS. Astrocyte-secreted matricellular proteins in CNS remodelling during development and disease. Neural Plast. 2014;2014 321209.

75. Malik AR, Liszewska E, Jaworski J. Matricellular proteins of the Cyr61/CTGF/ NOV (CCN) family and the nervous system. Front Cell Neurosci. 2015;9:237.

76. Jayakumar AR, Apeksha A, Norenberg MD. Role of matricellular proteins in disorders of the central nervous system. Neurochem Res. 2017:42(3):858-75.

77. Murtomäki S, Risteli J, Risteli L, Koivisto UM, Johansson S, Liesi P. Laminin and its neurite outgrowth-promoting domain in the brain in Alzheimer's disease and Down's syndrome patients. J Neurosci Res. 1992;32(2):261-73.

78. Palu E, Liesi P. Differential distribution of laminins in Alzheimer disease and normal human brain tissue. J Neurosci Res. 2002;69(2):243-56.

79. Wiksten $M$, Väänänen $A$, Liesi P. Selective overexpression of gamma1 laminin in astrocytes in amyotrophic lateral sclerosis indicates an involvement in ALS pathology. J Neurosci Res. 2007:85(9):2045-58.

80. Christopherson KS, Ullian EM, Stokes CCA, Mullowney CE, Hell JW, Agah A, et al. Thrombospondins are astrocyte-secreted proteins that promote CNS synaptogenesis. Cell. 2005;120(3):421-33.

81. Eroglu C, Allen NJ, Susman MW, O'Rourke NA, Park CY, Ozkan E, et al. Gabapentin receptor alpha2delta-1 is a neuronal thrombospondin receptor responsible for excitatory CNS synaptogenesis. Cell. 2009;139(2):380-92.

82. Rama Rao KV, Curtis KM, Johnstone JT, Norenberg MD. Amyloid- $\beta$ inhibits thrombospondin 1 release from cultured astrocytes: effects on synaptic protein expression. J Neuropathol Exp Neurol. 2013;72(8):735-44.

83. Son SM, Nam DW, Cha M-Y, Kim KH, Byun J, Ryu H, et al. Thrombospondin1 prevents amyloid beta-mediated synaptic pathology in Alzheimer's disease. Neurobiol Aging. 2015;36(12):3214-27.

84. Sidoryk-Wegrzynowicz M, Gerber YN, Ries M, Sastre M, Tolkovsky AM, Spillantini MG. Astrocytes in mouse models of tauopathies acquire early deficits and lose neurosupportive functions. Acta Neuropathol Commun. 2017;5(1):89. 
85. Willemsen MH, Nijhof B, Fenckova M, Nillesen WM, Bongers EMHF, CastellsNobau A, et al. GATAD2B loss-of-function mutations cause a recognisable syndrome with intellectual disability and are associated with learning deficits and synaptic undergrowth in Drosophila. J Med Genet. 2013;50(8): 507-14.

86. Kon T, Miki Y, Tanji K, Mori F, Tomiyama M, Toyoshima Y, et al. Localization of nuclear receptor subfamily 4, group A, member 3 (NR4A3) in Lewy body disease and multiple system atrophy. Neuropathol Off J Jpn Soc Neuropathol. 2015;35(6):503-9.

87. Vargas DM, De Bastiani MA, Zimmer ER, Klamt F. Alzheimer's disease master regulators analysis: search for potential molecular targets and drug repositioning candidates. Alzheimers Res Ther. 2018;10(1):59.

88. Heiland T, Zeitschel U, Puchades MA, Kuhn P-H, Lichtenthaler SF, Bjaalie JG, et al. Defined astrocytic expression of human amyloid precursor protein in Tg2576 mouse brain. Glia. 2019;67(2):393-403.

89. Avila-Muñoz E, Arias C. Cholesterol-induced astrocyte activation is associated with increased amyloid precursor protein expression and processing. Glia. 2015;63(11):2010-22.

90. Siman R, Card JP, Nelson RB, Davis LG. Expression of beta-amyloid precursor protein in reactive astrocytes following neuronal damage. Neuron. 1989;3(3): 275-85.

91. Rohan de Silva HA, Jen A, Wickenden C, Jen LS, Wilkinson SL, Patel AJ. Cellspecific expression of beta-amyloid precursor protein isoform mRNAs and proteins in neurons and astrocytes. Brain Res Mol Brain Res. 1997;47(1-2): 147-56.

92. Matsui T, Ingelsson M, Fukumoto H, Ramasamy K, Kowa H, Frosch MP, et al. Expression of APP pathway mRNAs and proteins in Alzheimer's disease. Brain Res. 2007:1161:116-23.

93. Byman E, Schultz N. Netherlands Brain Bank, Fex M, Wennström M. Brain alpha-amylase: a novel energy regulator important in Alzheimer disease? Brain Pathol Zurich Switz. 2018;28(6):920-32.

94. Byman E, Schultz N. Netherlands Brain Bank, Blom AM, Wennström M. A potential role for a-amylase in amyloid- $\beta$-induced astrocytic glycogenolysis and activation. J Alzheimers Dis JAD. 2019;68(1):205-17.

95. Nishimura H, Akiyama T, Irei I, Hamazaki S, Sadahira Y. Cellular localization of sphingosine-1-phosphate receptor 1 expression in the human central nervous system. J Histochem Cytochem Off J Histochem Soc. 2010;58(9): 847-56.

96. Van Doorn R, Van Horssen J, Verzijl D, Witte M, Ronken E, Van Het Hof B, et al. Sphingosine 1-phosphate receptor 1 and 3 are upregulated in multiple sclerosis lesions. Glia. 2010;58(12):1465-76.

97. Brana C, Frossard MJ, Pescini Gobert R, Martinier N, Boschert U, Seabrook TJ. Immunohistochemical detection of sphingosine-1-phosphate receptor 1 and 5 in human multiple sclerosis lesions. Neuropathol Appl Neurobiol. 2014:40(5):564-78.

98. Fukumoto K, Mizoguchi H, Takeuchi H, Horiuchi H, Kawanokuchi J, Jin S, et al. Fingolimod increases brain-derived neurotrophic factor levels and ameliorates amyloid $\beta$-induced memory impairment. Behav Brain Res. 2014; 268:88-93.

99. Hoffmann FS, Hofereiter J, Rübsamen H, Melms J, Schwarz S, Faber H, et al. Fingolimod induces neuroprotective factors in human astrocytes. J Neuroinflammation. 2015;12:184.

100. Aytan N, Choi J-K, Carreras I, Brinkmann V, Kowall NW, Jenkins BG, et al. Fingolimod modulates multiple neuroinflammatory markers in a mouse model of Alzheimer's disease. Sci Rep. 2016;6:24939.

101. Carreras I, Aytan N, Choi J-K, Tognoni CM, Kowall NW, Jenkins BG, et al. Dual dose-dependent effects of fingolimod in a mouse model of Alzheimer's disease. Sci Rep. 2019;9(1):10972.

102. Lee H-P, Pancholi N, Esposito L, Previll LA, Wang X, Zhu X, et al. Early induction of oxidative stress in mouse model of Alzheimer disease with reduced mitochondrial superoxide dismutase activity. PloS One. 2012;7(1): e28033.

103. Zhou Y, Song WM, Andhey PS, Swain A, Levy T, Miller KR, et al. Human and mouse single-nucleus transcriptomics reveal TREM2-dependent and TREM2independent cellular responses in Alzheimer's disease. Nat Med. 2020;26(1): 131-42.

104. Shibata N, Asayama K, Hirano A, Kobayashi M. Immunohistochemical study on superoxide dismutases in spinal cords from autopsied patients with amyotrophic lateral sclerosis. Dev Neurosci. 1996;18(5-6):492-8.

105. Blaauwgeers HG. Vianney de Jong JM, Verspaget HW, van den Berg FM, Troost D. Enhanced superoxide dismutase-2 immunoreactivity of astrocytes and occasional neurons in amyotrophic lateral sclerosis. J Neurol Sci. 1996; 140(1-2):21-9.

106. Martínez A, Carmona M, Portero-Otin M, Naudí A, Pamplona R, Ferrer I. Type-dependent oxidative damage in frontotemporal lobar degeneration: cortical astrocytes are targets of oxidative damage. J Neuropathol Exp Neurol. 2008;67(12):1122-36

107. Kobayakawa Y, Sakumi K, Kajitani K, Kadoya T, Horie H, Kira J-I, et al. Galectin-1 deficiency improves axonal swelling of motor neurones in SOD1(G93A) transgenic mice. Neuropathol Appl Neurobiol. 2015;41(2):227-44.

108. Starossom SC, Mascanfroni ID, Imitola J, Cao L, Raddassi K, Hernandez SF, et al. Galectin-1 deactivates classically activated microglia and protects from inflammation-induced neurodegeneration. Immunity. 2012;37(2):249-63.

109. Qu W, Wang Y, Wang J, Tang Y, Zhang Q, Tian D, et al. Galectin-1 enhances astrocytic BDNF production and improves functional outcome in rats following ischemia. Neurochem Res. 2010;35(11):1716-24.

110. Qu W-S, Wang Y-H, Ma J-F, Tian D-S, Zhang Q, Pan D-J, et al. Galectin-1 attenuates astrogliosis-associated injuries and improves recovery of rats following focal cerebral ischemia. J Neurochem. 2011;116(2):217-26.

111. Kasai A, Kinjo T, Ishihara R, Sakai I, Ishimaru Y, Yoshioka Y, et al. Apelin deficiency accelerates the progression of amyotrophic lateral sclerosis. PloS One. 2011;6(8):e23968.

112. Bao H-J, Zhang L, Han W-C, Dai D-K. Apelin-13 attenuates traumatic brain injury-induced damage by suppressing autophagy. Neurochem Res. 2015 Jan;40(1):89-97.

113. Bao $H$, Yang $X$, Huang $Y$, Qiu $H$, Huang G, Xiao $H$, et al. The neuroprotective effect of apelin-13 in a mouse model of intracerebral hemorrhage. Neurosci Lett. 2016;628:219-24.

114. Duan J, Cui J, Yang Z, Guo C, Cao J, Xi M, et al. Neuroprotective effect of Apelin 13 on ischemic stroke by activating AMPK/GSK-3ß/Nrf2 signaling. J Neuroinflammation. 2019;16(1):24.

115. Zhu J, Dou S, Jiang Y, Chen J, Wang C, Cheng B. Apelin-13 protects dopaminergic neurons in MPTP-induced Parkinson's disease model mice through inhibiting endoplasmic reticulum stress and promoting autophagy. Brain Res. 2019;1715:203-12.

116. Arnold SE, Arvanitakis Z, Macauley-Rambach SL, Koenig AM, Wang H-Y, Ahima RS, et al. Brain insulin resistance in type 2 diabetes and Alzheimer disease: concepts and conundrums. Nat Rev Neurol. 2018;14(3):168-81.

117. Heneka MT, Landreth GE, Hüll M. Drug insight: effects mediated by peroxisome proliferator-activated receptor-gamma in CNS disorders. Nat Clin Pract Neurol. 2007;3(9):496-504.

118. Nishida Y, Yokota T, Takahashi T, Uchihara T, Jishage K, Mizusawa H. Deletion of vitamin $E$ enhances phenotype of Alzheimer disease model mouse. Biochem Biophys Res Commun. 2006;350(3):530-6.

119. Nishida $Y$, Ito S, Ohtsuki S, Yamamoto N, Takahashi T, Iwata N, et al. Depletion of vitamin $\mathrm{E}$ increases amyloid beta accumulation by decreasing its clearances from brain and blood in a mouse model of Alzheimer disease. J Biol Chem. 2009;284(48):33400-8.

120. Perez-Nievas BG, Serrano-Pozo A. Deciphering the astrocyte reaction in Alzheimer's disease. Front Aging Neurosci. 2018;10:114.

121. Zhang Y, Sloan SA, Clarke LE, Caneda C, Plaza CA, Blumenthal PD, et al. Purification and characterization of progenitor and mature human astrocytes reveals transcriptional and functional differences with mouse. Neuron. 2016:89(1):37-53.

122. Mathys H, Davila-Velderrain J, Peng Z, Gao F, Mohammadi S, Young JZ, et al. Single-cell transcriptomic analysis of Alzheimer's disease. Nature. 2019; 570(7761):332-7.

123. Grubman A, Chew G, Ouyang JF, Sun G, Choo XY, McLean C, et al. A singlecell atlas of entorhinal cortex from individuals with Alzheimer's disease reveals cell-type-specific gene expression regulation. Nat Neurosci. 2019 Dec;22(12):2087-97.

\section{Publisher's Note}

Springer Nature remains neutral with regard to jurisdictional claims in published maps and institutional affiliations. 